EGG-WM- -9301

DE9 1006145

\title{
SUMMARY REPORT OF RESULTS OF THE VAPOR VACUUM EXTRACTION TEST AT THE RWMC
}

\author{
J. B. Sisson \\ G. C. Ellis \\ Published November 1990 \\ Idaho National Engineering Laboratory \\ EG\&G Idaho, Inc. \\ Idaho Falls, Idaho 83415 \\ Prepared For The \\ U.S. Department of Energy \\ Idaho Operations office \\ Under DOE Contract No. DE-AC07-76ID01570
}




\section{SUMMARY REPORT OF RESULTS OF THE VAPOR VACUUM EXTRACTION TEST AT THE RWMC}

Reviewed by:
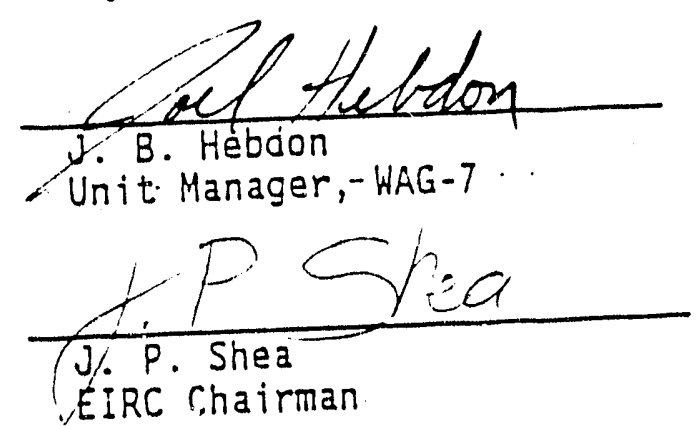

Approved by:

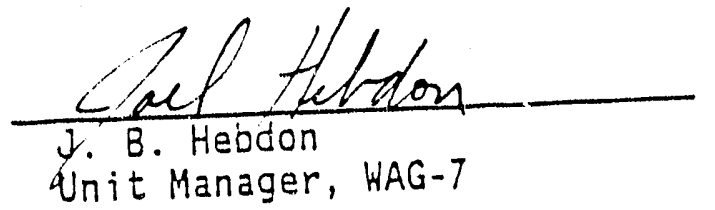

$$
\frac{11 / 21 / 90}{\text { Date }}
$$

$\frac{N O \hat{L}^{\prime} 1990}{\text { Date }}$

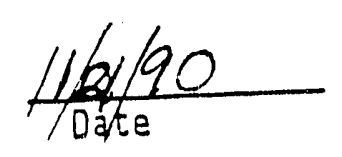




\begin{abstract}
A test scale vajor vacuum extraction system was operated for four months at the Radioactive Waste Management Complex. The extraction system removed more than 65 million $\mathrm{ft}^{3}$ of soil gas containing $429 \mathrm{Kg}$ of Carbon Tetrachloride and $164 \mathrm{Kg}$ of TCE. Hydraulic properties of the basalts were estimated and input into a numerical transport model. The model simulations indicated that a rubble zone at $190 \mathrm{ft}$ dominated the soil gas flow pattern. Refined calibration of transport models will allow enhancement of the production system design to increase operational efficiency and effectiveness.
\end{abstract}




\section{CONTENTS}

ABSTRACT ................................... i

ACRONYMS ............................ vi

1. INTRODUCTION . . . . . . . . . . . . . . . . . . . . . 1

1.1 Purpose ........................ . . 1

1.2 Background ...................... 1

1.3 VVE, An Alternative Removal Action . . . . . . . . . . . . 2

2. TEST SCALE VAPOR VACUUM EXTRACTION SYSTEM DESCRIPTION . . . . . . . 4

2.1 Extraction Well and Extraction System Hardware . . . . . . 4

2.2 Monitoring Wells .................. . 4

2.3 Data Acquisition System ................ . 9

2.4 Gas Sampling and Analysis System . . . . . . . . . . 10

3. TEST SCALE VAPOR VACUUM EXTRACTION SYSTEM OPERATIONS . . . . . . . . 11

3.1 Gas Sampling and Data Collection.............. 11

3.2 Data Acquisition System . . . . . . . . . . . . . 12

3.3 Data Analysis . . . . . . . . . . . . . . . . 13

3.3.1 Extraction Well . . . . . . . . . . . . . 13

3.3.2 Downhole Pressure Analysis . . . . . . . . . . 15

3.3.3 Gas Sampling Data . . . . . . . . . . . . . 18

4. GEOLOGICAL PROPERTIES, SYSTEM VARIABLES, AND OPERATION . . . . . . 26

4.1 Testing ...................... . . . 27

4.1.1 Tracer Tests - Cross Hole and Cross Port . . . . . . . 27

4.1.2 Sample Port Tests . . . . . . . . . . . . . . . 28

4.1.3 Flow Tests.................. . 28

5. TRANSPORT MODELING STATUS . . . . . . . . . . . . . . . 29

6. TEST SCALE VAPOR VACUUM SYSTEM OPERATION PROBLEMS AND

CORRECTIVE ACTIONS . . . . . . . . . . . . . . . . . . 32 


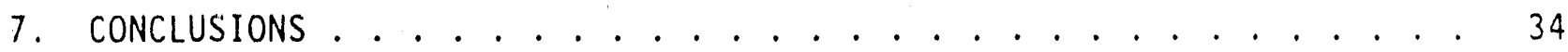

8. REFERENCES .......................... . . 35

APPENDIX A--THE FOUR MONTH TEST START/STOP TIMES . . . . . . . . . . . A A-I

APPENDIX B--PRODUCTION SCALE VAPOR VACUUM EXTRACTION SYSTEM
CONSIDERATIONS $\ldots \ldots \ldots$. . . B-1

\section{FIGURES}

1. TSVVE system at RWMC . . . . . . . . . . . . . . . . 5

2. Extraition well 89010 construction . . . . . . . . . . . 6

3. Extraction well and extraction system hardware . . . . . . . . . 7

4. Construction of typical sample port . . . . . . . . . . . . . . 8

5. Extraction flow rate vs time for TSUVE test . . . . . . . . . . . . 14

6. Wellbore flow test in the extraction well ........... 14

7. Vacuum pressure in the extraction well as a function

8. Barometric and downhole pressures from selected depths . . . . . . 16

9. Real part of transfer function . . . . . . . . . . . . . . . 17

10. Downhole pressure after correcting for barometric effects . . . . 17

11. Corrected downhole pressures with pump startup event . . . . . . . . 19

12. Concentration of $\mathrm{CCl}_{4}$ in the extraction stream . . . . . . . . . . 19

13. Cumulative $\mathrm{CC}_{4}, \mathrm{TCE}$ and $\mathrm{CCl}_{4}+\mathrm{TCE}$ extracted . . . . . . . . 20

14. Concentration of $\mathrm{CCl}_{4}$ as a function of depth in the monitoring wells..................... . 21

15. Concentration of $\mathrm{CCl}_{4}$ in monitoring well 88010 as a

function of time..................... . 22

16. Concentration of $\mathrm{CCl}_{4}$ in monitoring well $8902 \mathrm{D}$ as a

function of time...................... 23

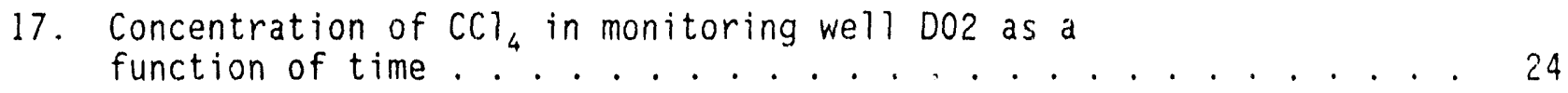

18. Soil gas flow pattern around the extraction well as a

function of depth and radius . . . . . . . . . . . . . . 30 


\section{ACRONYMS}

$\begin{array}{ll}\text { AID } & \text { Argon Ionization Detector } \\ \text { AWQC } & \text { ambient water quality criteria } \\ \mathrm{CCI}_{4} & \text { Carbon Tetrachloride } \\ \text { DAS } & \text { Data Acquisition System } \\ \text { GC } & \text { Gas Chromatograph } \\ \text { HEPA } & \text { high-efficiency particulate air } \\ \text { INEL } & \text { Idaho National Engineering Laboratory } \\ \text { PSVVE } & \text { production scale vapor vacuum extraction } \\ \text { QC } & \text { quality control } \\ \text { RWMC } & \text { Radioactive Waste Management Complex } \\ \text { SDA } & \text { Subsurface Disposal Area } \\ \text { SWEPP } & \text { Stored Waste Examination Pilot Plant } \\ \text { TSVVE } & \text { test scale vapor vacuum extraction } \\ \text { TSVVED } & \text { test scale vapor vacuum extraction demonstration } \\ \text { VOC } & \text { Volatile Organic Compound } \\ \text { VVE } & \text { vapor vacuum extraction }\end{array}$




\section{SUMMARY REPORT OF RESULTS OF THE VAPOR VACUUM EXTRACTION TEST AT THE RWMC}

\section{INTRODUCTION}

\subsection{Purpose}

The purpose of this report is to summarize the reasons for conducting the test scale vapor vacuum extraction demonstration (TSVVED) and to present the results of the four month test conducted at the Radioactive Waste Management Complex (RWMC). This report also discusses considerations in the design of a production scale vapor vacuum extraction (PSVEE) system.

\subsection{BACKGROUND}

In 1982 chlorinated volatile organic compounds (VOCs) were discovered at the RWMC (Leenheer and Bagby, 1982). By 1987, VOCs were found in the:

- Drinking water

- Samples of perched water

- Gas samples (from soil and vadose zones)

- Atmosphere above the soil surface (EG\&G, 1988).

The vocs found to date include:

- Carbon tetrachloride $\left(\mathrm{CCl}_{4}\right)$

- Trichloroethylene

- Chloroform 
- 1,1,1-trichloroethane

- 1,1,2-trichlorotrifluoroethane

- Tetrachlaroethylene.

These are common industrial solvents used to clean metal parts. In order to prevent further migration of Vocs that could result in unacceptable contaminant levels in the Snake River Plain Aquifer, a vapor vacuum extraction (VVE) system was considered (EGG, 1990).

\subsection{VVe, An Alternative Interim Remedial Action}

The VVE system is a process where contaminated soil gases are removed by pumping and displaced by atmospheric air. Therefore, the volume of the plume, and the rate and efficiency of the extraction process control the time required to cleanup the site.

A computer simulation of VOC transport was carried out for the RWMC to evaluate the feasibility of the VVE method (Baca, et al., 1988). The simulation indicated that VVE would be a viable techrology for contaminant removal. However, more accurate simulaticns of transport processes and better estimates of geological material properties at the RWMC will support final remediation.

VVE technology has been used at sites where the contaminated zones extend from ground surface to a ground water depth of less than $30 \mathrm{ft}$; however, the contaminant plume bereath the SDA extends from the ground surface to a ground water depth of $585 \mathrm{ft}$. Because the contaminant plume at the RWMC has 1000 - 10,000 timas more volume than plumes where $V V_{i}$ technology has been used, a system at least 100 times larger than a typical VVE system must be considered. Such a large scale system will require establishing operating characteristics under conditions found at the Idaho National Engineering Laboratory (INEL). Thus, a TSVVE system was designed, constructed, and 
installed at the RWMC to collect: (a) sufficient data for estimating geological material properties for transport modes, (b) to acquire experience in operating VVE systems under conditions found at the INEL, and (c) to evaluate the effectiveness for application as an interim remedial action. 


\section{TEST SCALE VAPOR VACUUM EXTRACTION SYSTEM DESCRIPTION}

The TSVVE system deployed at the RWMC consisted of an extraction well with sampling ports, an extraction pump and hardware used in its control (i.e., the extractor), five monitoring wells, a Data Acquisition System (DAS), and a gas sampling and analysis system. The physical layout of the TSVVE system is shown in Figure 1 where the five monitoring wells are denoted as 8801D, 8902D, D02,77-4, and WWW-1. The extraction well is indicated as 8901D.

\subsection{Extraction Well and Extraction System Hardware}

The extraction well was completed to a depth of $234 \mathrm{ft}$, cased from ground surface to $90 \mathrm{ft}$ and screened from 90-230 ft (Figure 2). The extraction well was connected to a centrifugal pump through an in-line heater, cyclone separator, high-efficiency particulate air (HEPA) filters, and a carbon bed absorber (Figure 3 ). The pump provided a vacuum source. The in-line heater provided relative humidity control to minimize moisture condensation in the filters and carbon beds. The cyclone separator and HEPA filters removed particulate from the flowstream. The carbon beds removed the VOCS from the extraction stream prior to its discharge to the atmosphere. To reduce $V O C$ discharges to the atmosphere following carbon bed saturation, a $V O C$ detector in the form of an HNU-201 gas analyzer sampled the discharge stream and shut down the TSVVE system when gross VOC concentrations exceeded 25 ppm. Once the HNu-201 gas analyzer shut down, a fresh carbon bed was valved on-line and the system was restarted. The VOC saturated carbon bed was then transported out of the RWMC to a EPA permitted recycling facility for replenishment of the carbon. All maintenance work was conducted in accordance with the Health and Safety Plan (Spang, 1990).

\subsection{MONitoring Wells}

Each of the five monitoring wells used in this test were equipped with sampling ports at des.ths ranging from 30-240 ft (Figure 4). Each well had 

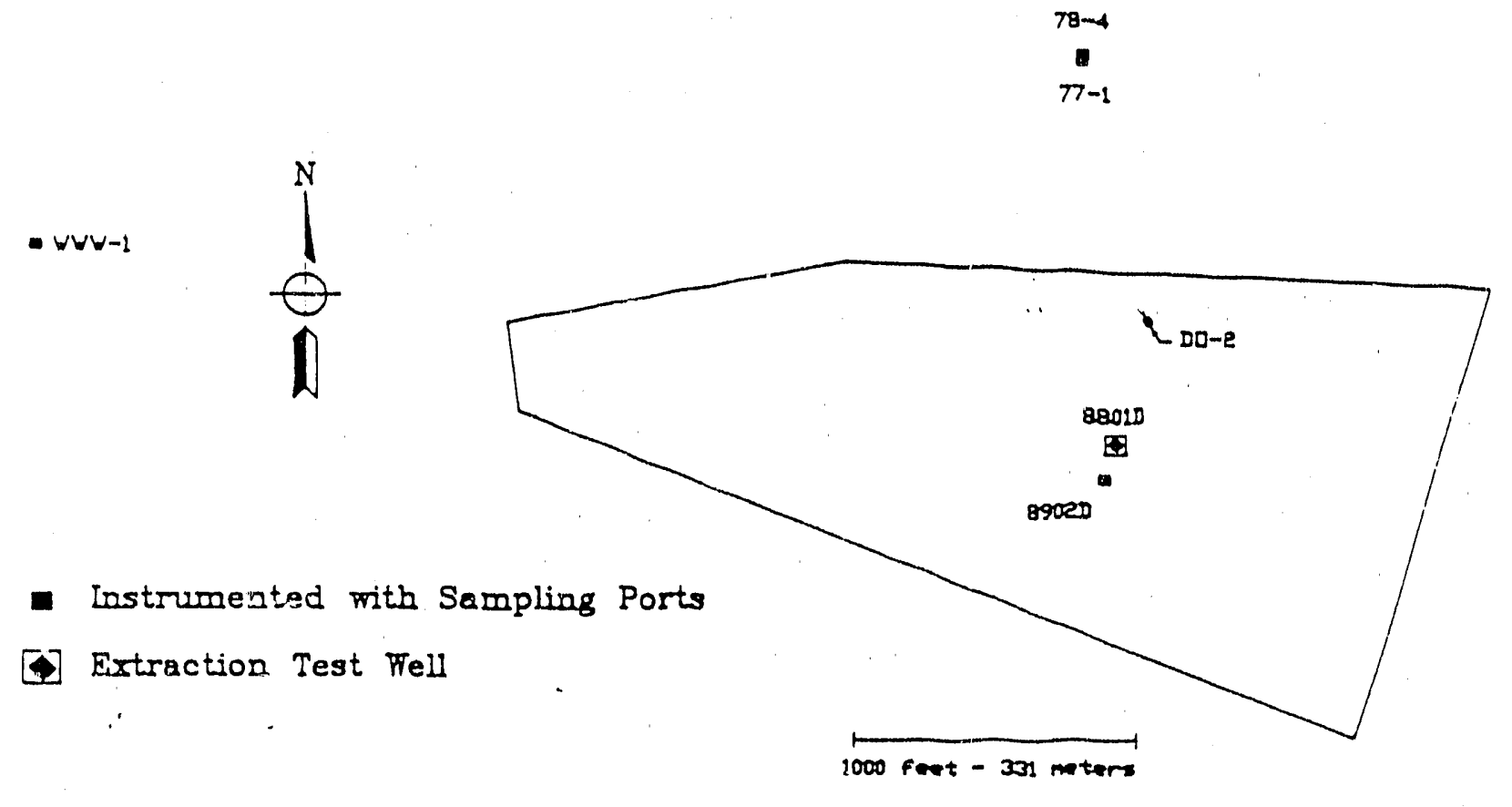

Figure 1. TSVVE system at RWMC. 


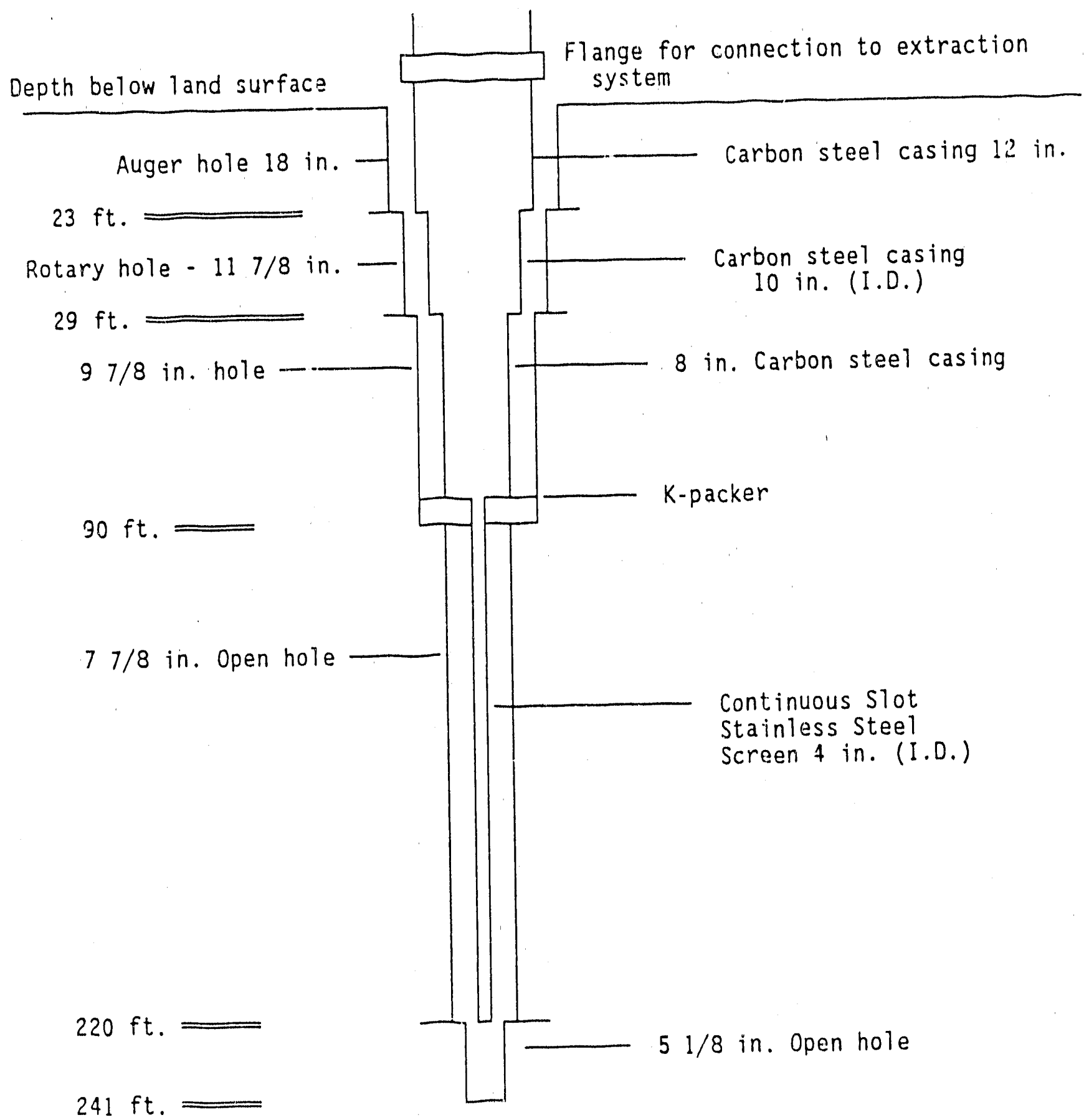

Figure 2. Extraction well 89010 construction. 


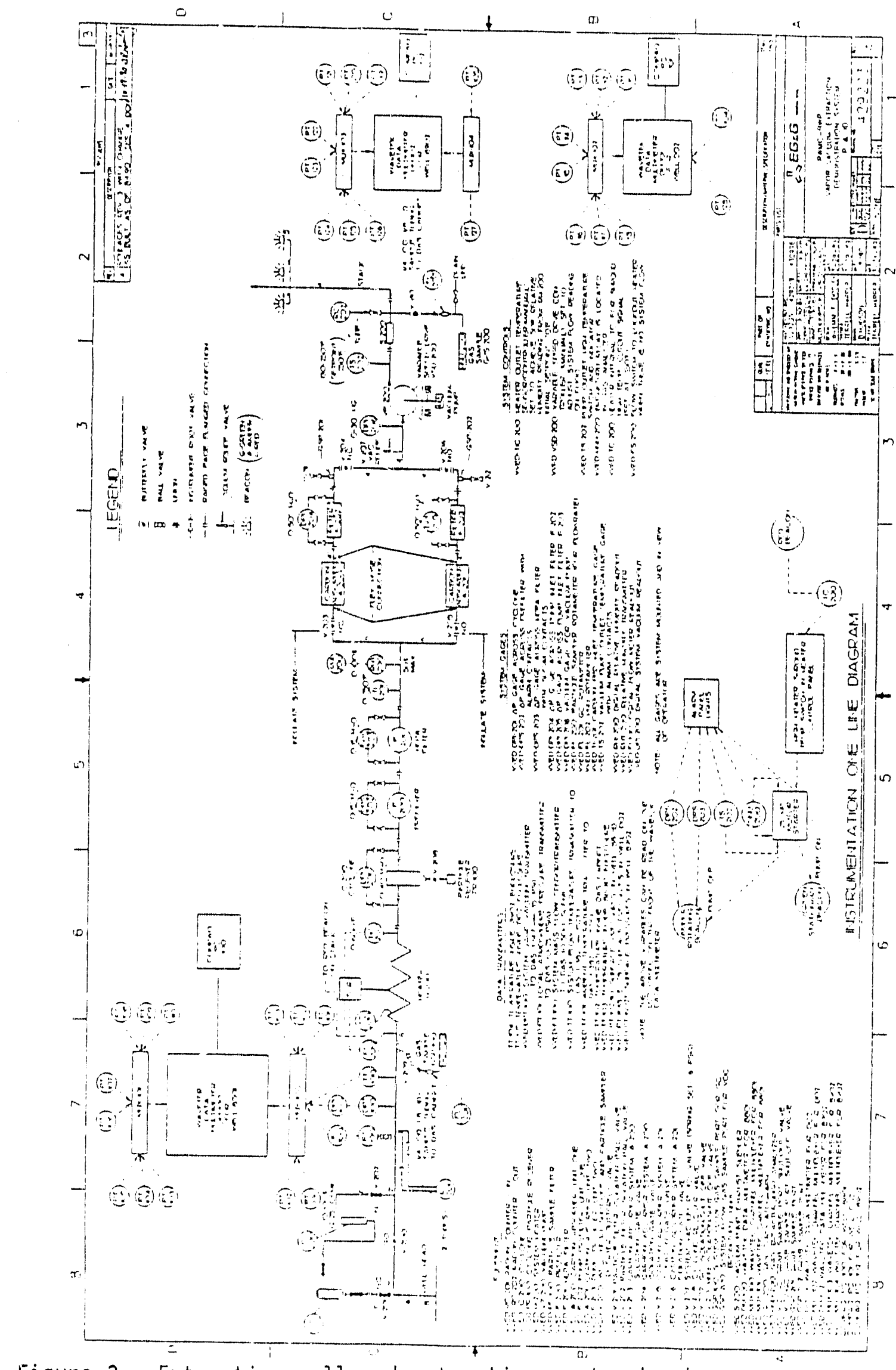

Figure 3. Extraction well and extraction system hardware. 


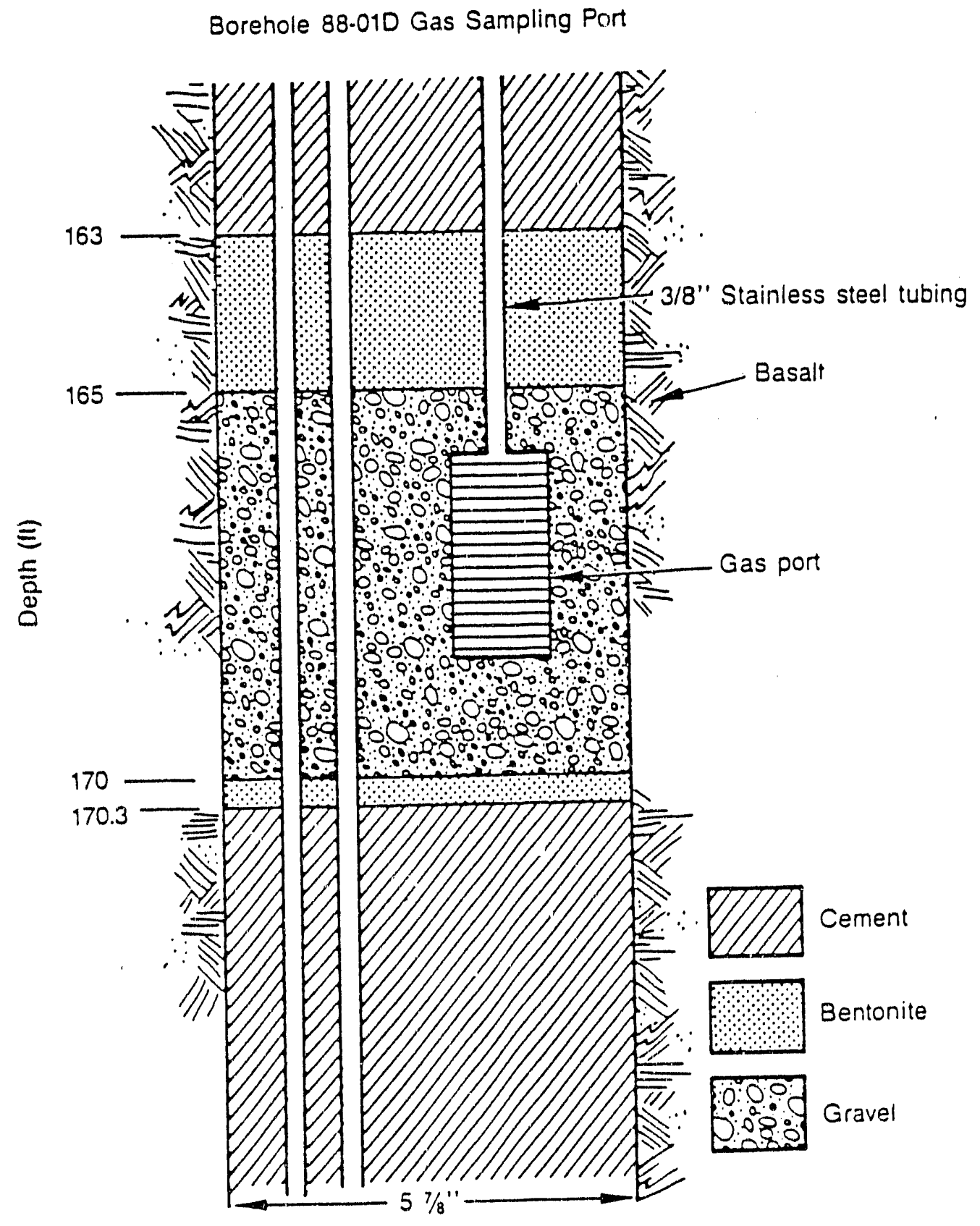

Figure 4. Construction of typical sample port. 
five to nine different sampling ports. All sample ports were constructed by centering a short length of stainless steel well screen at the desired depth and packing a $5-\mathrm{ft}$ section of the wellbore with gravel. ihe gravel pack was capped with a bentonite plug and the wellbore was filled with cement to the elevation of the next sample port. Each well screen was connected to the ground surface by $3 / 8$-in stainless steel tubing.

Three of the monitoring wells were located inside the SDA. The sampling ports within thos? wells were terminated at ground surface using a pressure transducer and sample-pump connection. The two wells located outside the SDA were used only for gas sampling purposes due to their distance from the extraction well.

\subsection{Data Acouisition System}

Data were acquired at the extraction well and the three surrounding monitoring wells inside the SDA using a variety of transducers connected to WaveTek Model 52A data loggers. These data loggers have an analog to digital conversion resolution of $\pm 0.0001 \mathrm{~V}$, and a stability accuracy of $\pm 0.005 \%$ of range. The data loggers were connected to Compaq SLT/286 portable computers for data storage.

For the purpose of measuring pressure fluctuations both downhole and at ground surface, the monitoring wells were instrumented with Setra Model 270 absolute pressure transducers. These pressure transducers have a measurement range of 600 - 1100 mbar and a voltage output of $0-5 \mathrm{~V} d c$. This output is specified by the manufacturer to have operational uncertainties of $\pm 0.1 \%$ of range for its set zero reading $(600 \mathrm{mbar})$, a preset gain uncertainty of $\pm 0.1 \%$, and a voltage linearity of $\pm 0.5 \%$ for output data. Thus, the transducers and. data loggers have a combined measurement uncertainty of \pm 0.60 mbar.

The extraction well was instrumented with a Kurz Model 555 flow meter for measuring stream flow; a Setra Model C239 differential pressure transducer for measuring the vacuum generated in the system by the extraction process; 
and three type $T$ thermocouples for monitoring ambient temperature, stream temperature, and DAS enclosure temperature. An uncertainty analys is was performed on the system as a whole.

\subsection{Gas Sampling and Analysis System}

A Scentograph Plus PC portable system gas chromatograph (GC) was used to measure concentrations of the contaminant. The Gî was calibrated to $225 \mathrm{ppm}$ benzene; response factors relative to benzene were established to identify target compounds stored in an internal industrial solvent library. The GC was equipped with a $6-\mathrm{ft}, 3 \% \mathrm{SP}-10 \mathrm{C}$ ? packed column and an argon ionization detector (AID) (Rauen, 1990).

A sample was introduced to the column by connecting the Tedlar sample bag to an external GC sainple port with Teflon tubing and a Tygon nipple. The sample was pumped to a sample loop (approximacely $3 \mathrm{in}$ ) and valved to the column. The excess sample was automatically purged from the system. Each Tedlar sample bag was purged and used a maximum of five times. Random blanks were run on a daily basis as a quality control (QC) measure to assure system memory or carryover contamination did not occur. Further, $\mathrm{CCl}_{4}$ standards (i.e., Scott Speciaity Gas, certified $\pm 2 \%$ ) of $205 \mathrm{ppm}$ and $1000 \mathrm{ppm}$ were run on a daily basis to ensure a linear $\mathrm{CCl}_{4}$ response from approximately $100 \mathrm{ppm}$ to 1000 ppm (Rauen, 1990). 


\section{TEST SCALE VAPOR VACUUM EXTRACTION SYSTEM OPERATIONS}

The operating principle of the TSVVE system was to apply a vacuum to the extraction well head and adsorb the VOCs on an activated charcoal bed (See Figure 2). The soil gases removed by the vacuum system are displaced by clear air entering across the ground surface. Appendix A provides a calendar of pump events based on DAS data sets and the hand written operations log kept at the RWMC.

\subsection{Gas Saitpling and Data Collection}

Gas analyses were performed on three types of samples:

- Tedlar bag samples from the extraction well (89010) process stream

- Tedlar bag samples from monitoring wells 88010, 89020, D02, WWW-1, and $78-4$

- Continuous samples of the stack effluent.

At the extraction well Tedlar bag samples were collerted through a Swagelok quick connect located $15 \mathrm{ft}$ downstream from the wellhead. The three monitoring wells located within the SDA $(8801,8902$, and D02) were sampied on a weekly basis while the outlying wells (WWW-1 and 78-4) were sampled on a biweekly basis. Gas samples from all monitoring wells were collected following the same procedures. Each sample port was purged three volumes. A 1-L, 2-mil Tedlar sampling bag (SKC Inc., Part \#232-01) was connected to a Xitech Vacuum Sample Collection Box. A Swagelok quick connect connected a sample line from the box to the purged well sampling port. The sample pump created a vacuum in the sample box forcing well gas into the sample bag without contaminating the pump. The bag was labeled in conjunction with the procedures outlined in the Sample and Analysis Plan (Rauen, 1990). When samples from each sampling point of a well were collected, they were 
transported, for analysis, to the GC located at the RWMC Stored waste Examination Pilot Plant (SWEPP) facility.

A process stack effluent stream was continuously sampled by a panel mounted $\mathrm{HNu}-201$ gas analyzer. In accordance with manufacturers recommendation, the system was calibrated at least weekly with certified $92.7 \mathrm{ppm}$ isobutylene. If a concentration of $25 \mathrm{ppm}$ gross VOCs was detected and maintained for five seconds, the $\mathrm{HNu}-201$ gas analyzer was programmed to shut down the TSVVE system. The HNU-201 gas analyzer was equipped with an $11.7 \mathrm{eV}$ lamp which was capable of ionizing the chlorinated VOCs of interest. Each photoionization lamp had a life expectancy of approximately 300 hours, which created a need for frequent maintenance (Rauen, 1990).

All sampling and maintenance work was conducted in accordance with the Health and Safety Plan (Spang, 1990).

\subsection{Data Acouisition System}

All points of data were collected by the DAS at 2 min intervals. Data were time stamped for each scan and kept in chronological order in a large file on the Compaq portable computer. Every three or four days the data were transferred to a floppy disk for processing and storage (Rauen, 1990). There were some intervals of data lost due to a programming error in the software on the WaveTek data loggers. These losses occurred infrequently, but did result in the loss of 24 hours of data each time they occurred. There were a total of 72 hours of data lost by the DAS for wells 88010 and 89010,48 hours of data lost for well 8902D, and 48 hours of data lost for well D02. These losses had no signiricant impact on the analyses of the data because:

- An adequate number of barometric cycles were found in other intervals of data.

- Pump on/off events occurred during intervals when DAS was operational. 


\subsection{Data Analysis}

\subsubsection{Extraction Well}

Data acquired by the DAS for extraction well points were used to calculate the following parameters for the TSVVE four month test:

- Average flow

- Average vacuum/pressure

- The relationship between flow and vacuum

- Average extraction stream temperature.

Over the four months of operation the TSVVE system operated at two flow rates, 492 and $678 \mathrm{scfm}$. The $678 \mathrm{scfm}$ flow rate was attained following the installation of a larger vacuum pump. The TSVVE system operated a total of 2088 hours. If the two week shut down required for new pump installation was not considered, the TSVVE system ran more than $80 \%$ of its planned schedule. Figure 5 summarizes the flow rates over the four month test.

Appendix A contains a record of TSVVE system pump events and causes for system shut down. While there are 20 shut down events listed as unknown, these events were later attributed to a faulty HNu-201 gas analyzer ionization tube. Overall the system performed reliably and with low maintenance while removing a total of $65 \mathrm{milli}$ ion $\mathrm{ft}^{3}$ of soil gas, 53 million $\mathrm{ft}^{3}$ at $492 \mathrm{scfm}$ and 12 million $\mathrm{ft}^{3}$ at $678 \mathrm{scfm}$.

During the four month test, a wellbore flow test was carried out in the extraction well. The results are shown in Figure 6 . It was determined that approximately half of the soil gas extracted ame from above the $110 \mathrm{ft}$ interbed and the remaining gas was extracted from a basalt rubble zone 


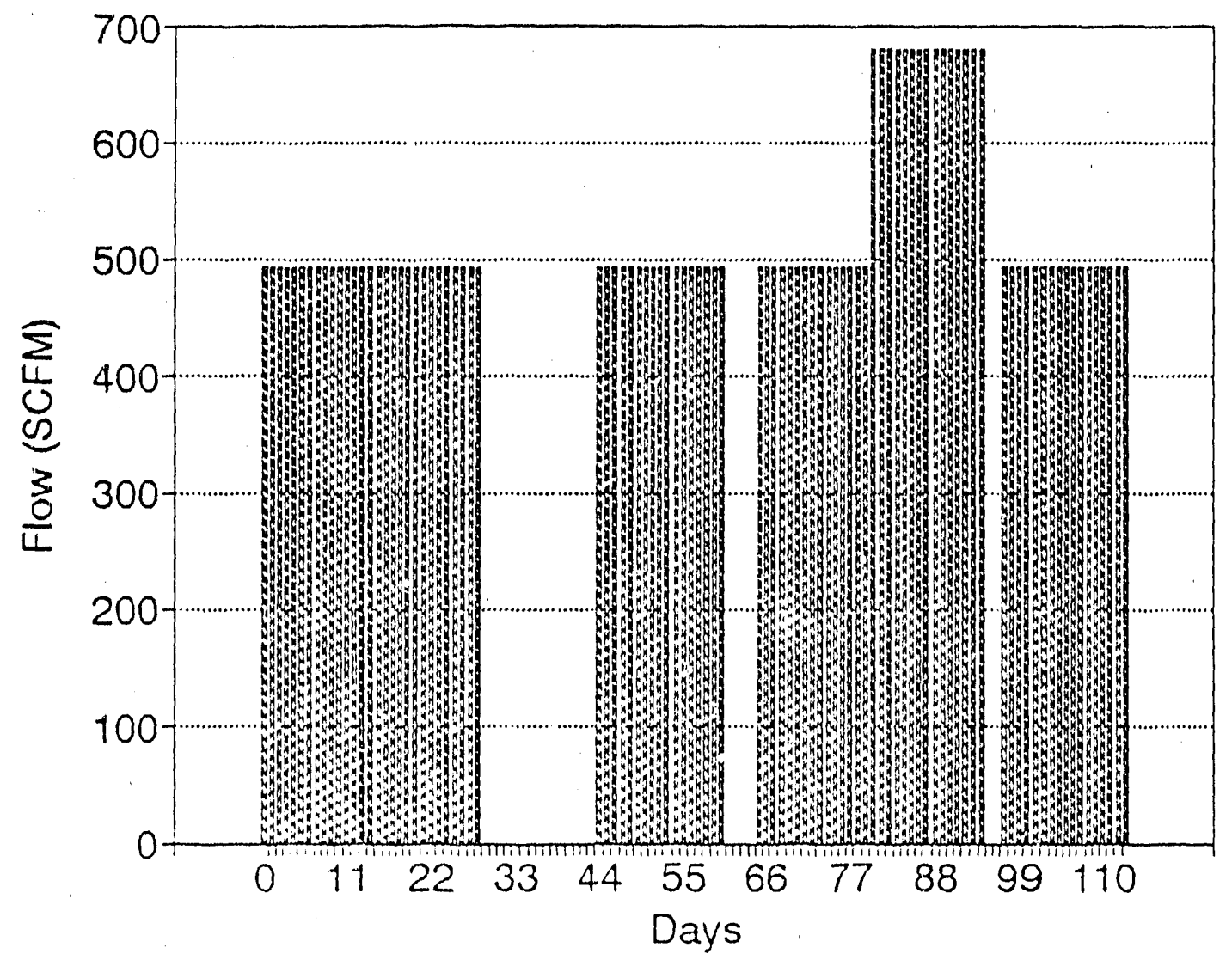

Figure 5. Extraction flow rate vs time for TSVVE test.

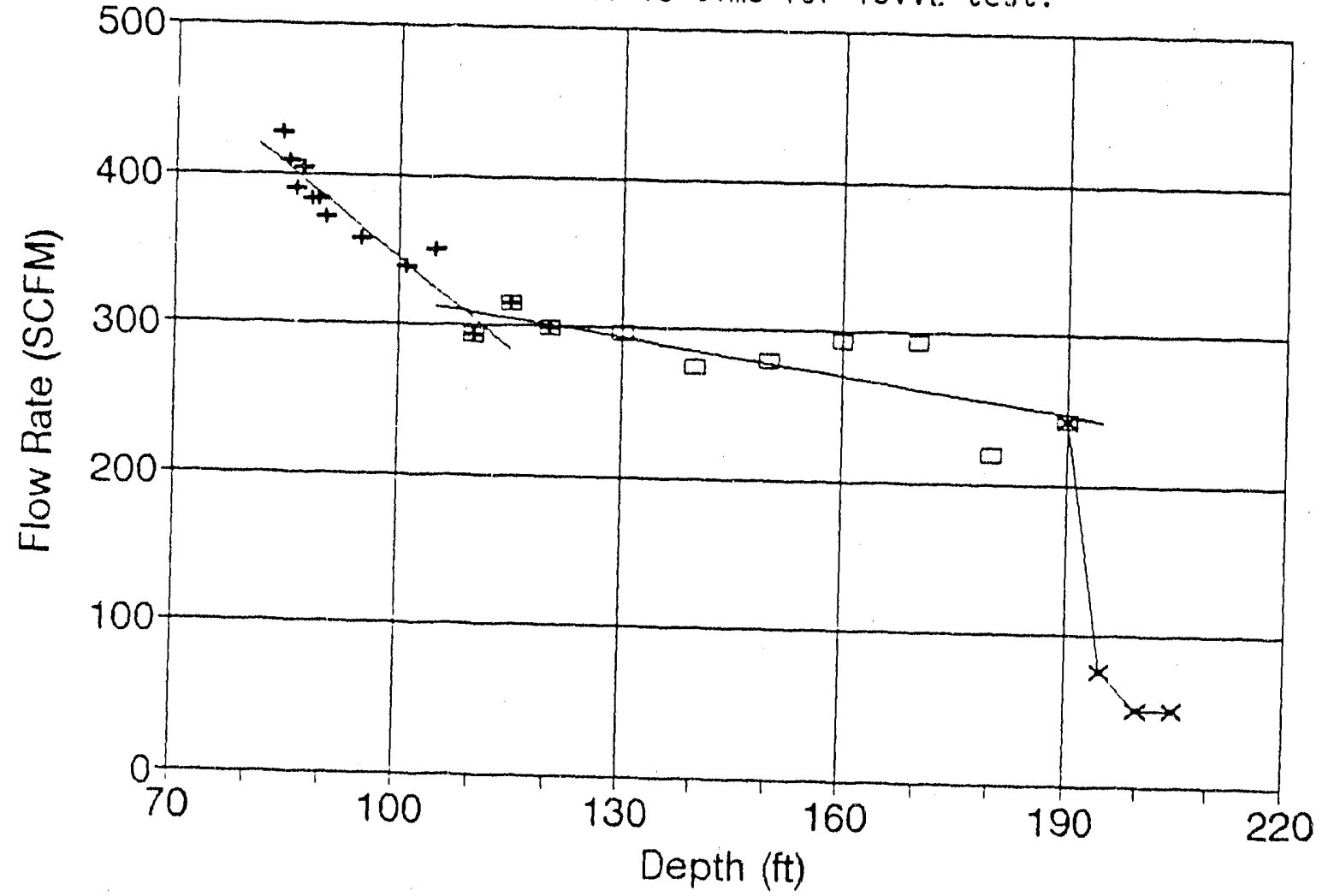

Figure 6. Wellbore flow test in the extraction well. 
at 190 - $195 \mathrm{ft}$. While the precision of the wellbore flow test was 7 imited by the presence of the well screen, it indicates that the rubble zone strongly affected soil gas flow patterns. Removal of the well screen would allow a more precise evaluation.

A test comparing pressure and flow was developed from operations data by pairing flow rates with vacuum pressures while the TSVVE was running. The results of this test are shown in Figure 7 and indicate that only 0.5 psi of vacluum develop d in the wellbore at $678 \mathrm{scfm}$. These results indicate that 2,000 - 3,000 scfm flow rates are achievable with the existing well. All data were considered analytical support II data.

\subsubsection{Downhole Pressure Analys is}

The downhole and barometric pressures obtained during the four month test are shown in Figure 8 . As can be seen, the downhole pressures lagged the barometric pressure and were more pronounced at greater depths. Also, the downhole pressures appear to be smoother than the barometric pressure and again the effect is more pronounced at greater depths. Figure 8 also indicates that it will be difficult to see any pressure changes in the downhole pressure caused by the TSVVE system. Thus, the barometric pressure effects must be removed before an accurate evaluation can be made. The barometric pressure effects can be removed by fourier analysis.

A Fourier series was fitted to the barometric and downhole pressures using standard techniques. The resulting Fourier series had a different amplitude at each frequency and the ratio of the downhole to barometric amplitudes are shown in Figure 9. Figure 9 shows that the higher the frequency the lower the ratio of downhole to barometric amplitudes. Figure 9 is also referred to as the real part of the transfer function that relates downhole to barometric pressure. The phase angle or lag can also be plotted versus frequency and is known as the imaginary part of the transfer function. Once the real and imaginary parts of the transfer function are known, a downhole pressure can be estimated from the barometric pressure. The estimated pressures were subtracted from the measured values and the differences are shown in Figure 10. 


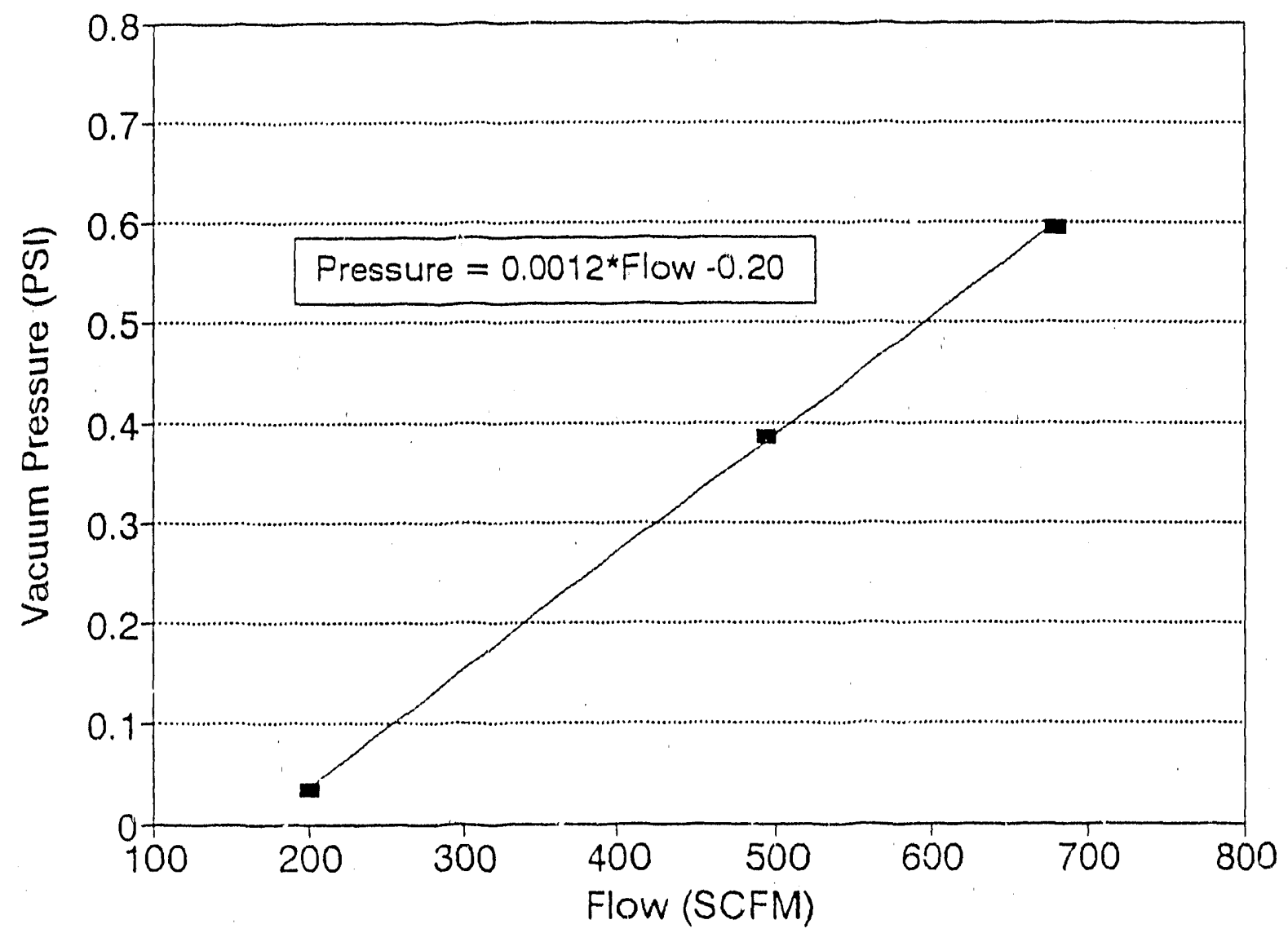

Figure 7. Vacuum pressure in the extraction well as a function of flow rate.

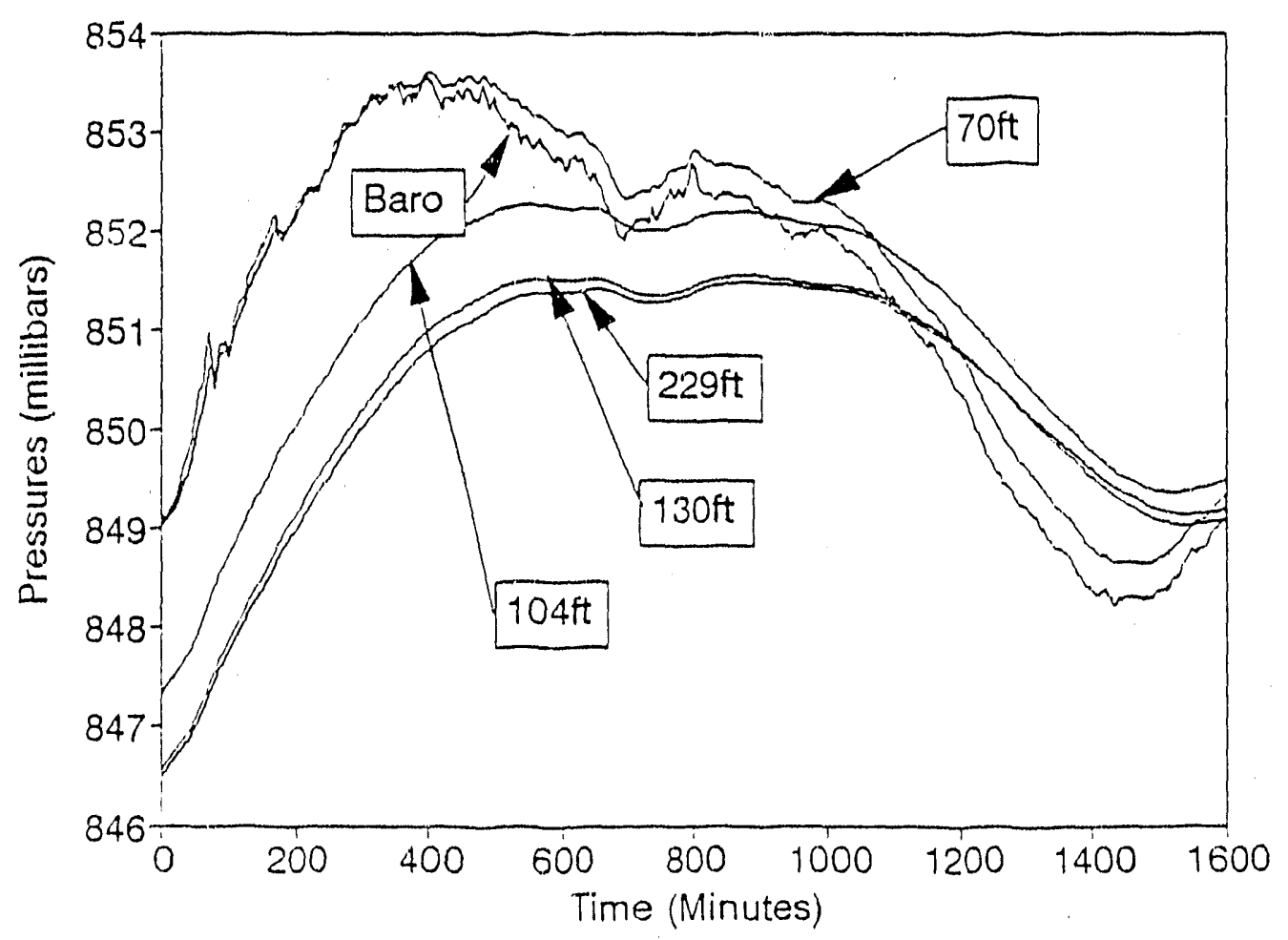

Figure 8. Barometric and downhole pressures from selected depths. 


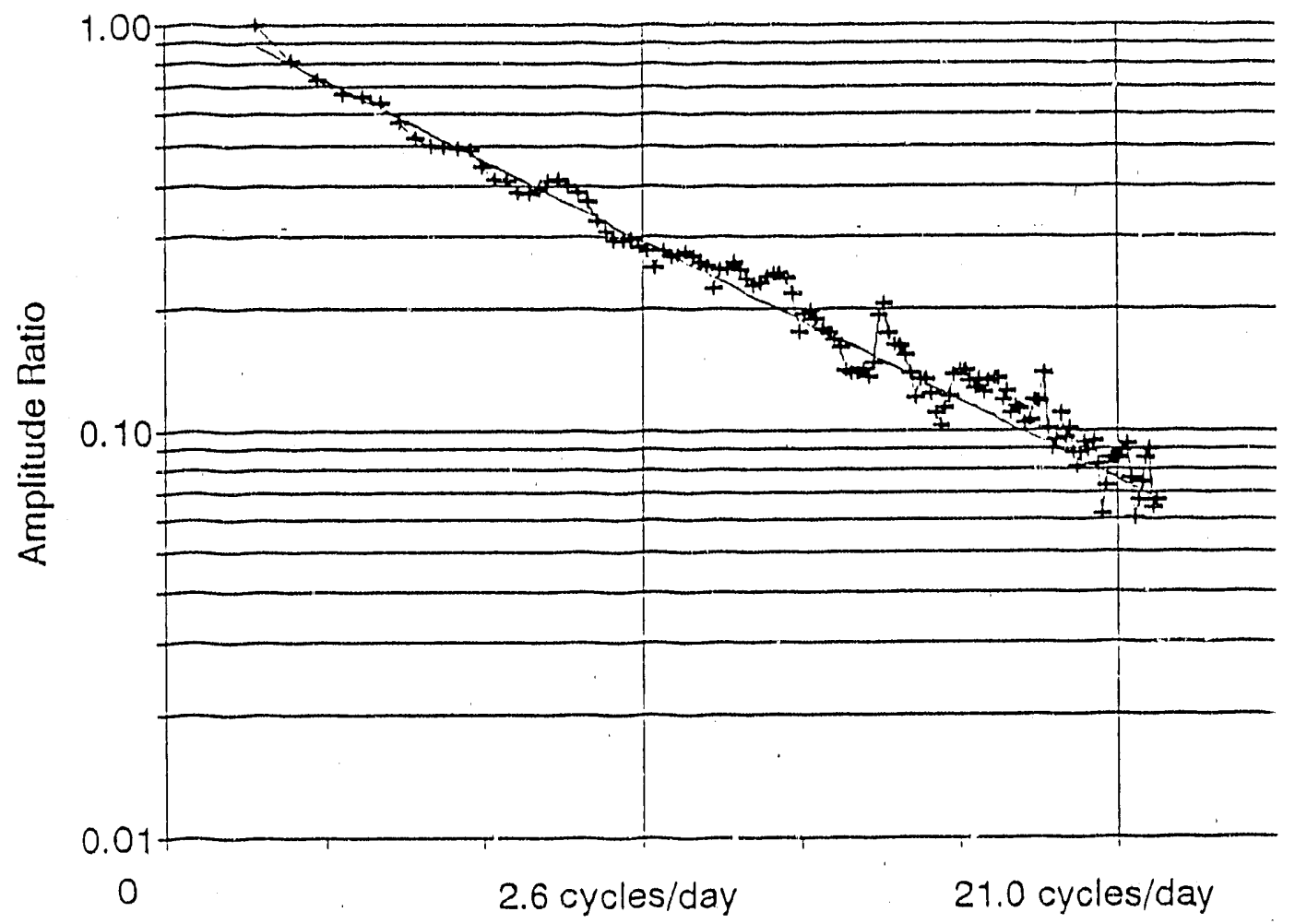

Figure 9. Real part of transfer function.

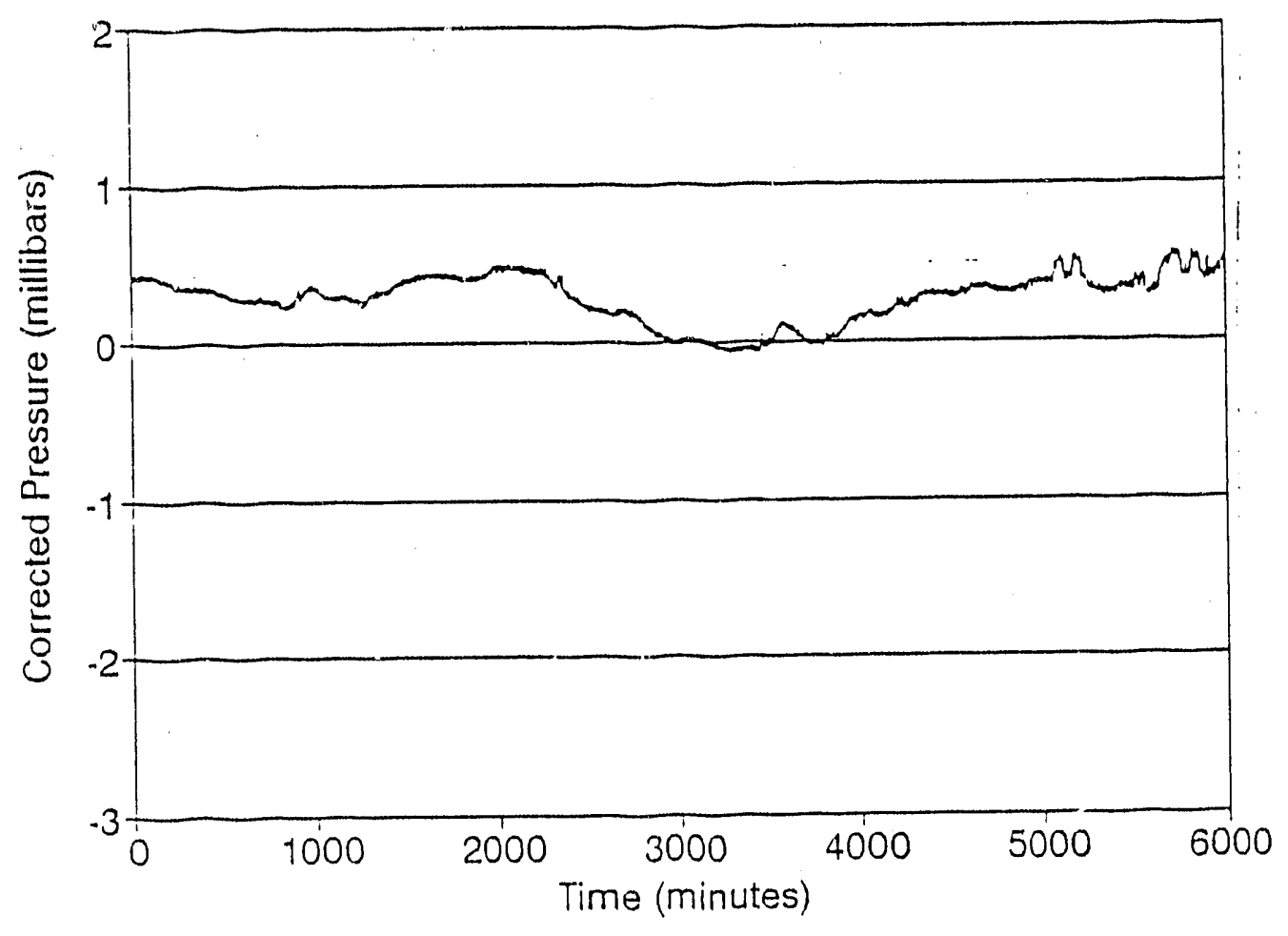

Figure 10. Downhole pressure after correcting for barometric effects. 
While the curve shown in Figure 10 deviates from the ideal level line, it does indicate that most of the barometric effects have been removed from the downhole data. Although the uncorrected downhole data ranged over 10 mbar, the corrected data had a range of about $0.6 \mathrm{mbar}$. The transfer function methodology was applied to an interval of data that spanned a pump startup event. This is shown in Figure 11. The pump startup event is now clearly visible and the magnitude of the pressure change can be used to estimate the large scale hydraulic properties required in the modeling effort.

An added benefit of computing the transfer functions is that the vertical hydraulic conductivities can be estimated from the slope of the transfer function (Carslaw and Jaeger, 1959). The conductivities estimated from the transter function ranged from 0.1 to $4.5 \mathrm{~m} / \mathrm{d}$. Vertical conductivities are also required by the transport model.

\subsubsection{Gas Sampling Data}

Concentrations of VOCS were estimated from gas samples obtained from the extraction stream while the TSWVE system was operating. Concentrations of $\mathrm{CCl}_{4}$ obtained over the four month test period are shown in Figure 12 . The concentrations averaged from $232 \pm 81 \mathrm{mg} / \mathrm{m}^{3}$ for $\mathrm{CCl}_{4}$ and $87 \pm 25 \mathrm{mg} / \mathrm{m}^{3}$ for TCE.

Cumulative totais of $\mathrm{CCl}_{4}$, TCE, and $\mathrm{CCl}_{4}+$ TCE removed from the basalts over time are shown in Figure 13. Only the $\mathrm{CCl}_{4}$ and TCE concentrations are shown because they accounted for $94 \%$ of the $V^{n}$; extracted. The cumulative values were computed using the flow rates shown in Figure 5 and the four month concentration average. Figure 13 indicates that the extraction process resulted in $429 \mathrm{Kg}$ of $\mathrm{CCl}_{4}, 164 \mathrm{Kg}$ of TCE, for a total of $593 \mathrm{~kg}$ of combined $\mathrm{CCl}_{4}$ and TCE being removed from the basalt. Further, using the results of Walton et al (1988), the TSVVE system removed $9.5 \%$ of the $\mathrm{CCl}_{4}$ and $16 \%$ of the TCE present in the vapor phase. 


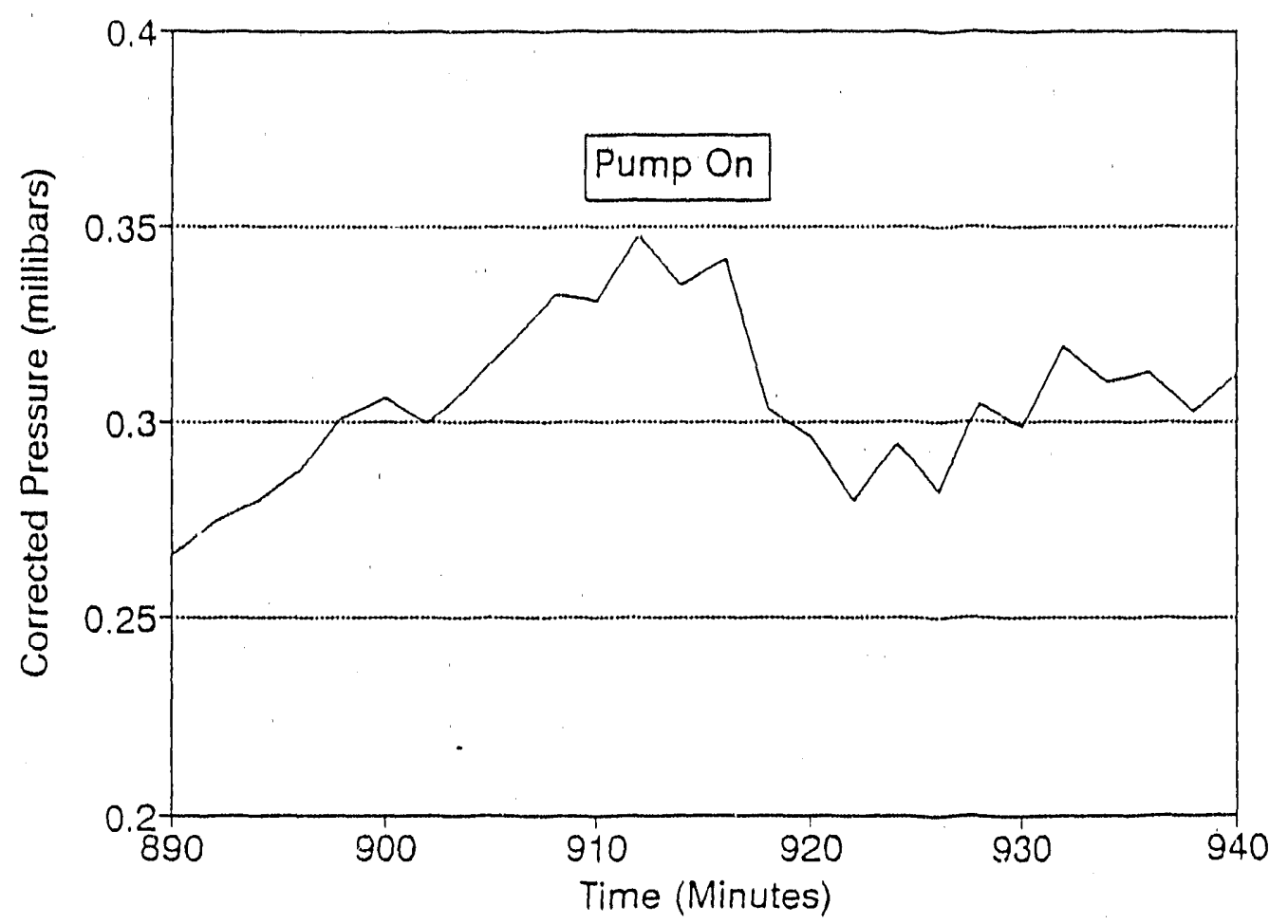

Figure 11. Corrected downhole pressures with pump startup event.

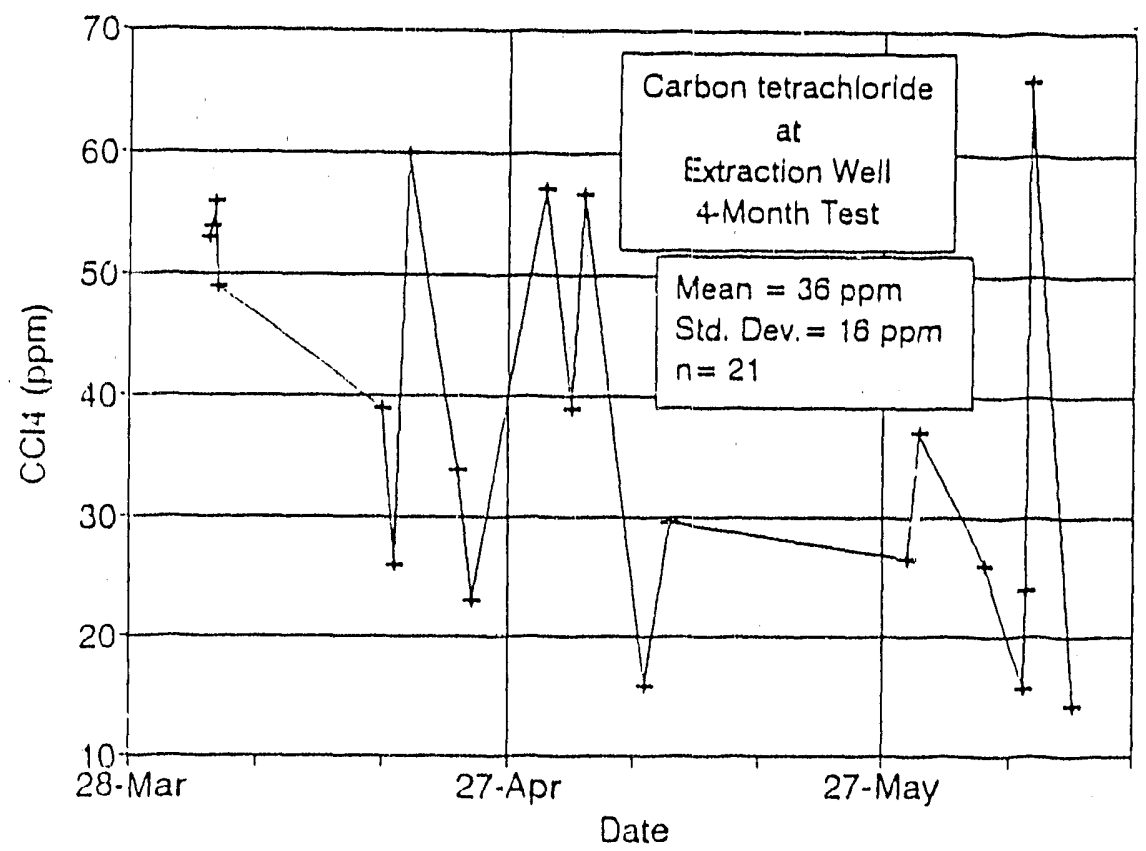

Figure 12. Concentration of $\mathrm{CCl}_{4}$ in the extraction stream. 


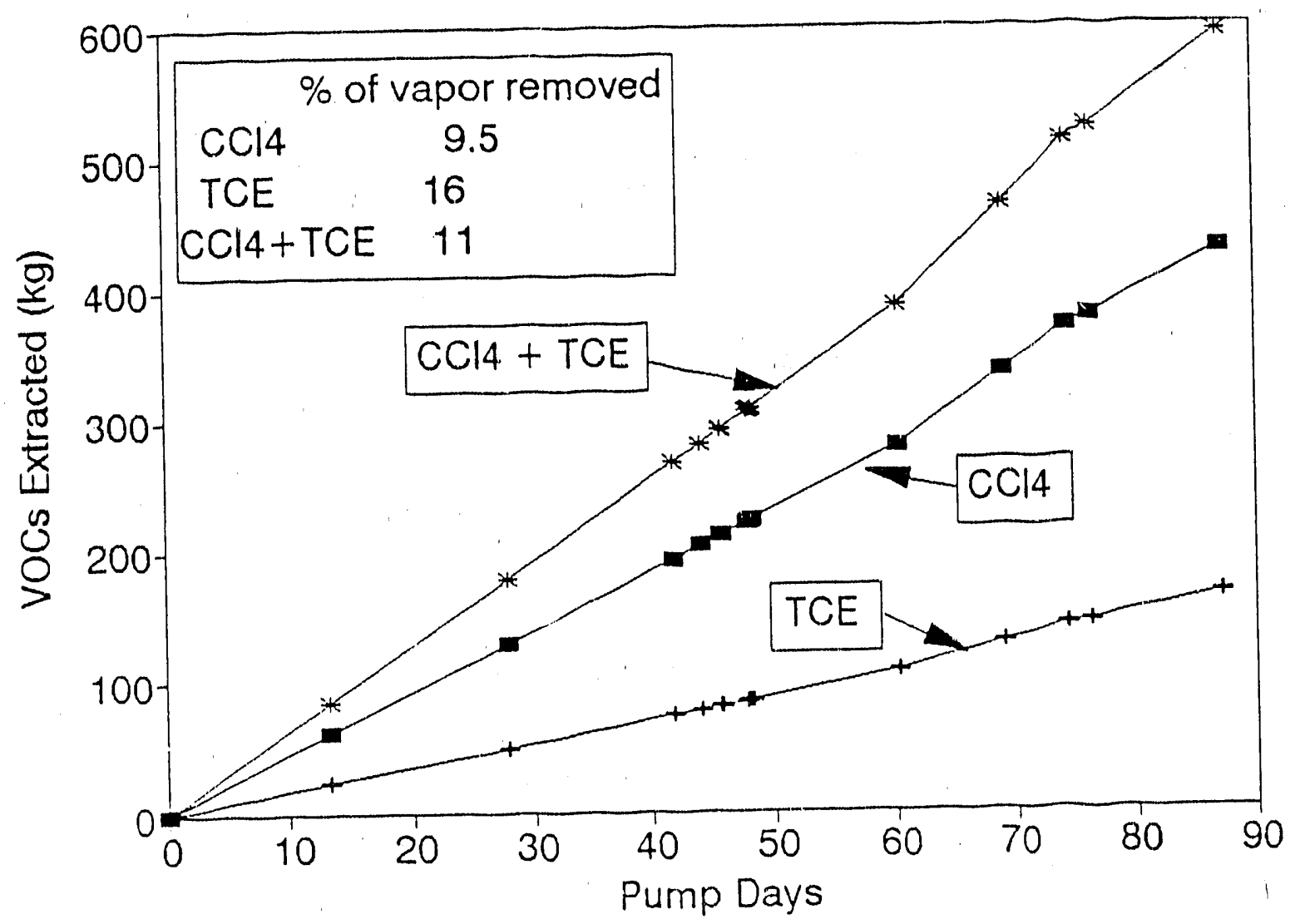

Figure 13. Cumulative $\mathrm{CC}_{4}$, TCE and $\mathrm{CCl}_{4}+$ TCE extracted.

The VOCs in the vapor phase represent $3 \%$ of the total VOC disposed, $13 \%$ remains in the original disposal containers, and $84 \%$ of the VOCs have diffused to the atmosphere.

The four month average concentration of $\mathrm{CCl}_{4}$ was plotted versus depth for each monitoring well inside the SDA (i.e., 88010, 8902D and D02) and is shown in Figure 14. In general, the concentration of $\mathrm{CCl}_{4}$ increases with depth to about $100 \mathrm{ft}$ then decreases toward $240 \mathrm{ft}$. The general features of these plots (i.e., the large bulge at depth) were predicted with numerical transport models and referred to as the dying source term effect. The dying source term effect results from very high concentrations occurring in the waste pits and trenches following disposal of VOCs. As $\mathrm{CCl}_{4}$ diffuses from the trenches, depleting the buried wastes of $\mathrm{CCl}_{4}$, concentrations in the upper regions are reduced. As diffusion continues $\mathrm{CCl}_{4}$ is transported toward deeper depths and upward through the soil surface. Thus, the high concentration bulge develops and appears to move downward although total vocs in the vadose 
8801D

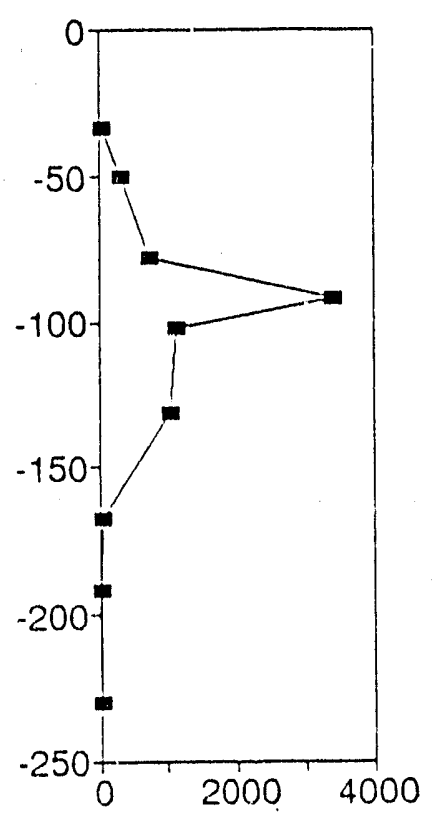

8902D

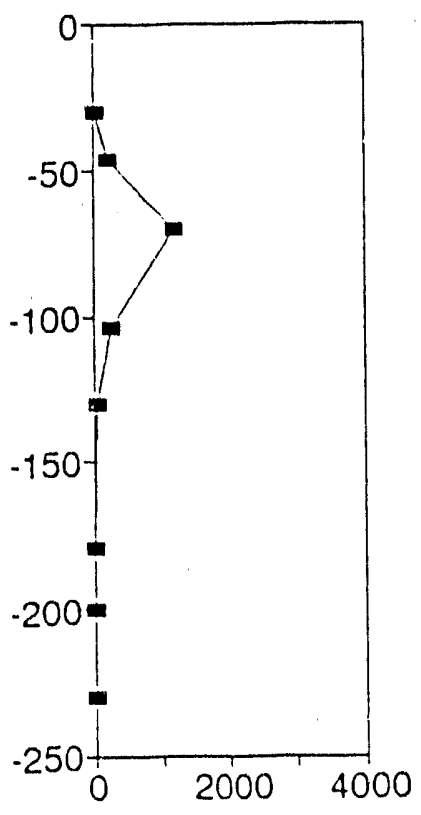

DO2

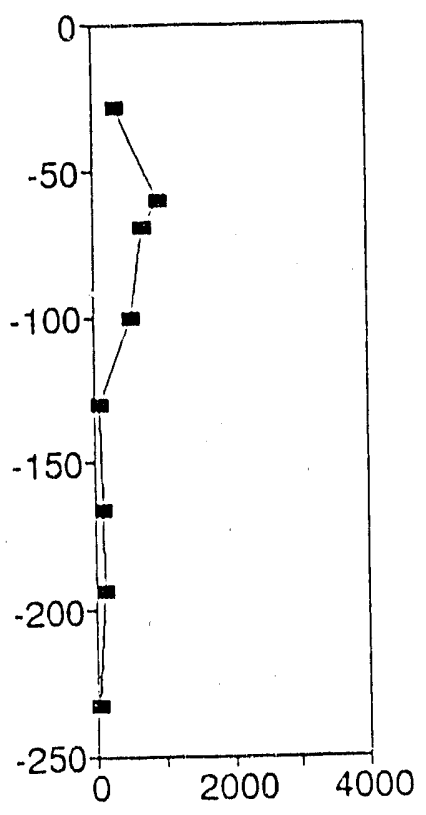

Figure 14. Concentration of $\mathrm{CCl}_{4}$ as a function of depth in the monitoring wells.

zone decrease with time (Walton et al, 1988). The $\mathrm{CCl}_{4}$ concentration in well 88010 at $92 \mathrm{ft}$ is greater than $3000 \mathrm{ppm}$. These high concentrations may also be occurring in wells 89020 and 002 , however, since there are no ports located at $92 \mathrm{ft}$ in $8902 \mathrm{D}$ or 002 ; this high concentration would be missed. These results indicate that placement of ports, based on logs of the wellobre, should be enhanced with actual concentration measurements at each proposed sampling port location. Figure 14 was constructed using the average values shown in Figures 15,16 , and 17 . The upper portion of Figure 15 shows $\mathrm{CCl}_{4}$ concentration values below $92 \mathrm{ft}$. The concentrations at and above $92 \mathrm{ft}$ do not indicate any clear trend with time. The $\mathrm{CCl}_{4}$ concentrations at 102 and $131 \mathrm{ft}$ show an increase with time, possibly indicating the buige in the plume is migrating downward with pumping operations. Since half the extracted volume of gas was found to be coming from the $192 \mathrm{ft}$ rubble zone, the downward movement of the plume would be expected. Also, the large volume of gas being obtained from the rubble zone at 190 to $195 \mathrm{ft}$ indicates upward movement that would account for decreasing concentrations of $\mathrm{CCl}_{4}$ seen at 192 and $230 \mathrm{ft}$. 

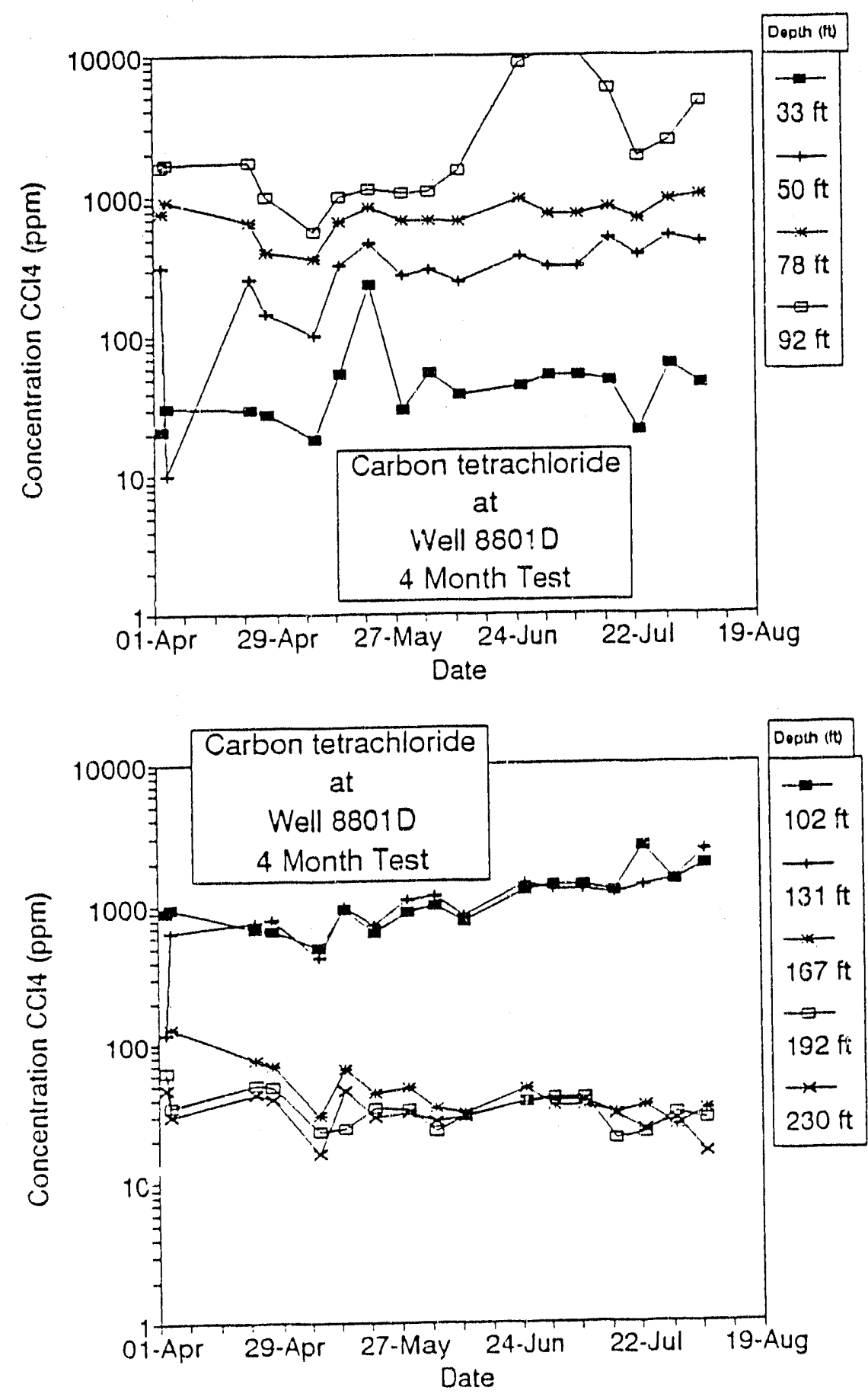

Figure 15. Concentration of $\mathrm{CCl}_{4}$ in monitoring well 88010 as a function of time. 

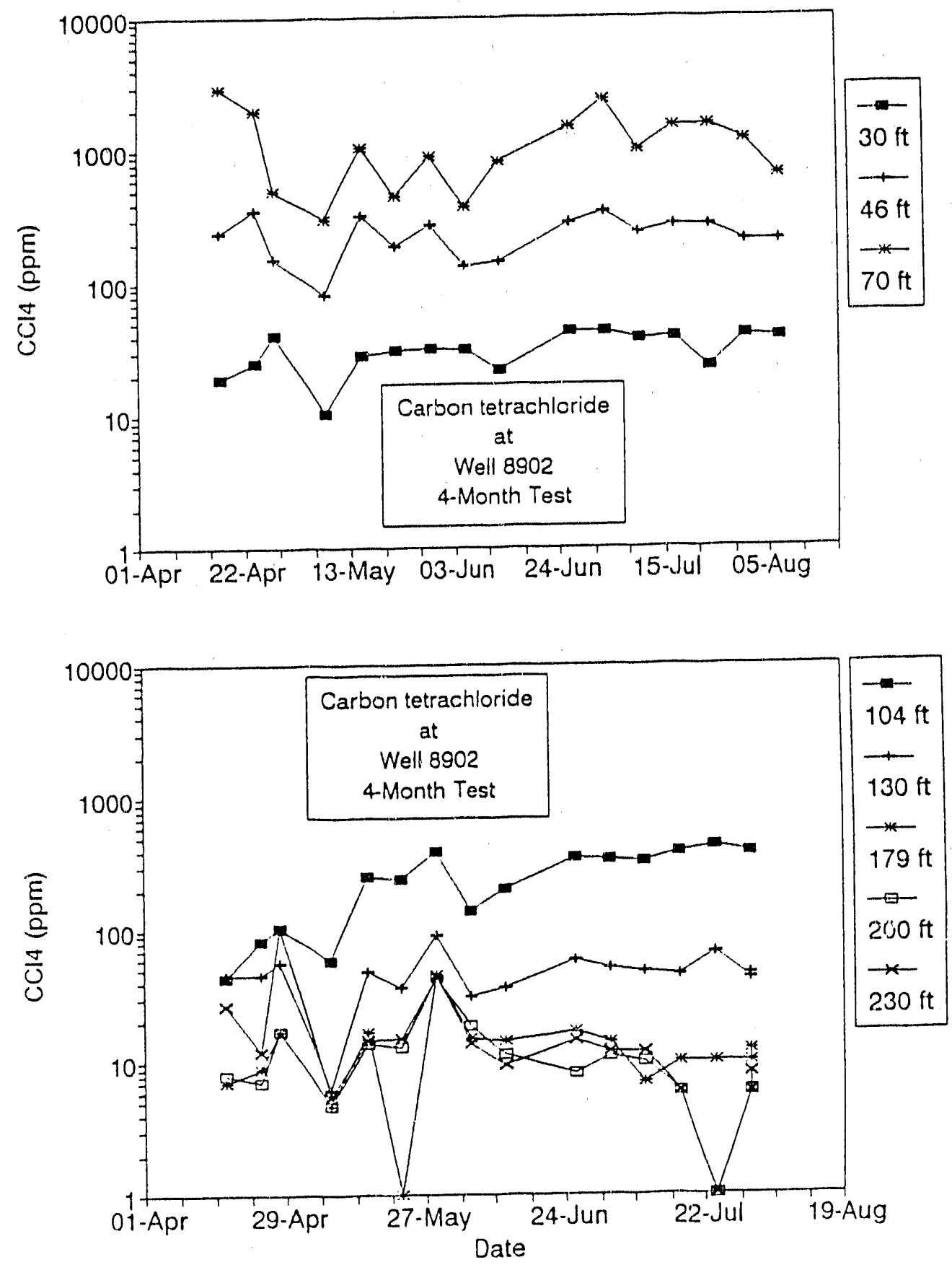

Figure 16. Concentration of $\mathrm{CCl}_{4}$ in monitoring well $8902 \mathrm{D}$ as a function of time. 

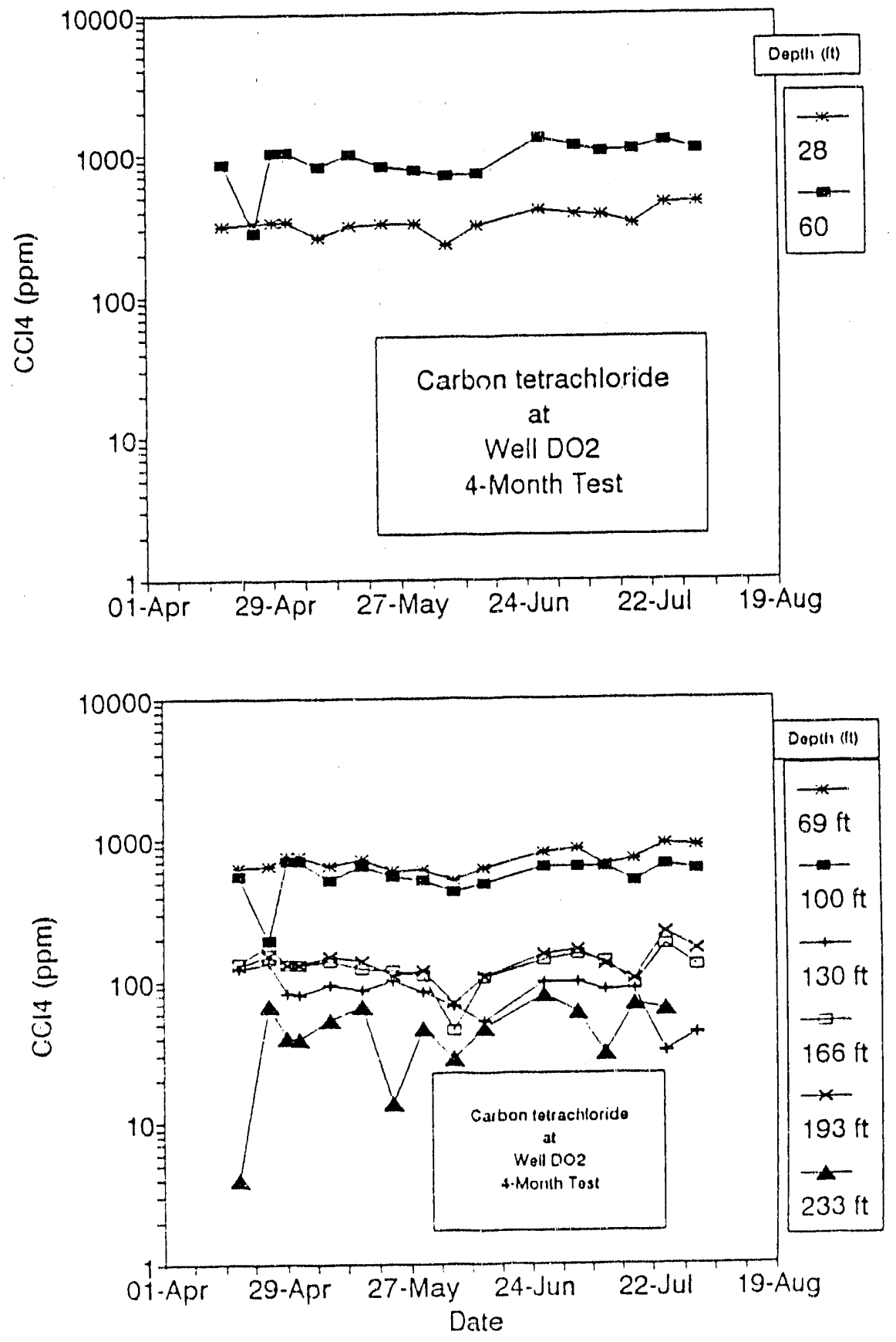

Figure 17. Concentration of $\mathrm{CCl}_{4}$ in monitoring well DO2 as a function of time. 
Extended operation of a year or more at the $500 \mathrm{scfm}$ extraction rate, would yield verifications of these explanations. Also, numerical modeling would scrve to validate these findings. While the trends at 102, 131, 192, and 230 $\mathrm{ft}$ are easily explained, the decreasing concentration at $167 \mathrm{ft}$ over time does not fit well with this model of system behavior.

Figure 16 shows the $\mathrm{CCl}_{4}$ concentrations at well 8902D over time. The only possible trend occurring at this monitoring well was found at $104 \mathrm{ft}$. The apparent increase in $\mathrm{CCl}_{4}$ concentrations over time is the result of relatively. low $\mathrm{CCl}_{4}$ concentrations found for the first four samples analyzed. Thus, the apparent trend could have resulted from sample port purging effects following installation of the monitoring ports.

Figure 17 is the result of $\mathrm{CCl}_{4}$ analysis done at well 002 . 


\section{GEOLOGICAL PROPERTIES, SYSTEM VARIABLES, AND OPERATION}

The volume of soil gas that can be removed from beneath the SDA is directly proportional to porosity. Thus, more accurate estimates of the underlying basali porosity will lead to an improved es imate of the amount of VOC contaminant to be removed by VVE. Also, the time needed for remediation will be better determined if the total volume of contaminated gas to be processed is known. While porosity is a geological controlling variable for total volume of soil gas to be extracted, hydraulic conductivity is the geological control determining the rate the extraction process can be carried out. Thus, improved estimates of hydraulic properties will contribute to sizing of future extraction equipment.

Estimates of the porosity of the basalt can be substantially improved through the analyses of carefully executed tracer tests. Both smal? ard large scale tests can be performed. Small local scale tests will establish an improved correlation between basalt type and porosity. Large scale tests will establish the effective porosity of the layered system under the SDA. The small scale local test can be carried out within single borehoies by injecting a tracer gas into one sample port and monitoring its concentration in adjacent sample ports. Tinis test would also lead to improved estimates of the diffusion coefficients of VOCS in the basalt. While the TSVVE system is in: operation, large scale porosities can be estimated from data obtained while injecting a tracer into a sampling port and monitoring concentration at the extraction well. In addition to large scale porosity, estimates of dispersion coefficients can be computed from data sets obtained during this test.

As new wells are added to the extraction system, pump tesis, using open boreholes, should be conducted prior to installing gas ports to ensure the pumping rates are adequate for the permeability estimates. Also, using inflatable packers to construct the monitoring sampling port systems would allow the borehole to be converted to an extraction well should triat be desired at a later date. Convertible wells would lead to a more flexible 
design in that cleanup of high concentration zones could proceed before cleanup of large volumes of basalt contaminated with relatively 1 ww concentrations of VOCs.

At present, there is little information regarding vacuum pressure relative to flow rate through the basalt at high Reynolds numbers. A significant ancunt of this informaiion is readily obtainable from packer tests conducted on the existing well (89010) while operating the TSVVE system over a wide range of flow conditions. These results would support the feasibility of using very large extractors and only a few wells to achieve rapia cleanup.

\subsection{Testing}

\subsubsection{Tracer Tests - Cross Hole and Cross Port}

Improved estimates of the travel ismes from point to point in the subsurface would enhance our understanding of transport phenomena. Based on the small pressure difference observed between the wells during pumping, the travel times jetween well 88010 and the extraction well are believed to be short. Thus, if a tracer were injected at well 88010 , it would arrive within the extraction stream in a few days (perhaps hours). Deviation from this pattern would indicate sorption to be a significant factor. If this were true, rapid cleanup would be impacted. Conversely, if the travel times were found to be imore rapid than current expectations, the effective porosity could be less than current estimates and leac to accelerated cleanup. The tracer test can be done from monitoring well to extraction well and also from sample port to sample port within a monitoring well. These 'ests will improve the current estimates of the volume of soil gas that will be pumped, provide verification of current models, and thus improve the design of a PSVVE system. 


\subsubsection{Sample Port Tests}

The sample port tests conducted at the monitoring wells were intended to provide data for horizontal conductivity estimates. Results of these tests were inconclusive due to the pressure drop generated by flow through the $3 / 8$-in tubing connecting the sample port to the ground surface. This was particularly true for gas ports located in areas of high permeability. In order to eliminate the effects of this head loss, the pressure must be monitored in the sampling port.

To further determine properties of the basalts, pump tests using inflatable packers need to be carried out. These tests will provide data for conductivity estimates and data for improving estimates of the plume distribution under the KWMC.

\subsubsection{Flow Tests}

Flow tests performed in the extraction well identified two intervals dominating the extraction process. However, the presence of the well screen in the extraction well prevented precise measurements of flow. Thus, to better quantify the properties of the intervals dominating the extraction process, flow tests with the well screen removed are required. The test procedure used should also provide the use of inflatable packers to permit isolation of dominating intervals. Thus, allowing larger pressure changes to be seen at the monitoring well. 


\section{TRANSPORT MODELING STATUS}

The transport modeling effort will provide information to enhance the PSVVE system design and eventual cleanup of the organic contaminants. Further PSVVE system design considerations are given in Appendix B. The current modeling effort involves a full three-dimensional transient simulation beginning from the growth of the VOC plume upon emplacement of the wastes to the cleanup of the subsurface using various VVE configurations. This model incorporates the most recent and up-to-date information regarding subsurface geometry, source term strength and locations, and hydraulic and transport properties.

Preliminary to the three-dimensional model, a iwo-dimensional axisymmetric model was developed for calibration purposes. This preliminary model includes laterally continuous basalt layers, sedimentary interbeds, and the 190-ft rubble zone. In addition to being used to obtain large-scale estimates for soil properties, this model has also provided insights into the possible flow patterns that exist around the current extraction well. The calibration process was initiated by using the vertical conductivity estimates from barometric data and then adjusting these to match the observed flow rates from the extraction well flow test. The flow pattern and corresponding travel times resulting from the calibration process (assuming a 500 scfm pump rate) are shown in Figure 18. The flow lines indicate that for intervals extending several feet above the $110-\mathrm{ft}$ interbed, flow is nearly horizontal toward the we11. One reason why concentration changes could not be seen above $110 \mathrm{ft}$ is that the plume is moving horizontally in this region. Thus, as soil gas is being removed it is replaced by gases of nearly the same concentration.

The effect of the 190-ft rubble zone on the flow of soil gas can also be seen in Figure 18. The figure indicates a strong upward pattern in flow toward $190 \mathrm{ft}$. This vertical flow suggests soil gases of low VOC concentraticn are being drawn from depths below $240 \mathrm{ft}$. Thus, concentrations in the monitoring wells from below $190 \mathrm{ft}$ should decrease with pumping. This 


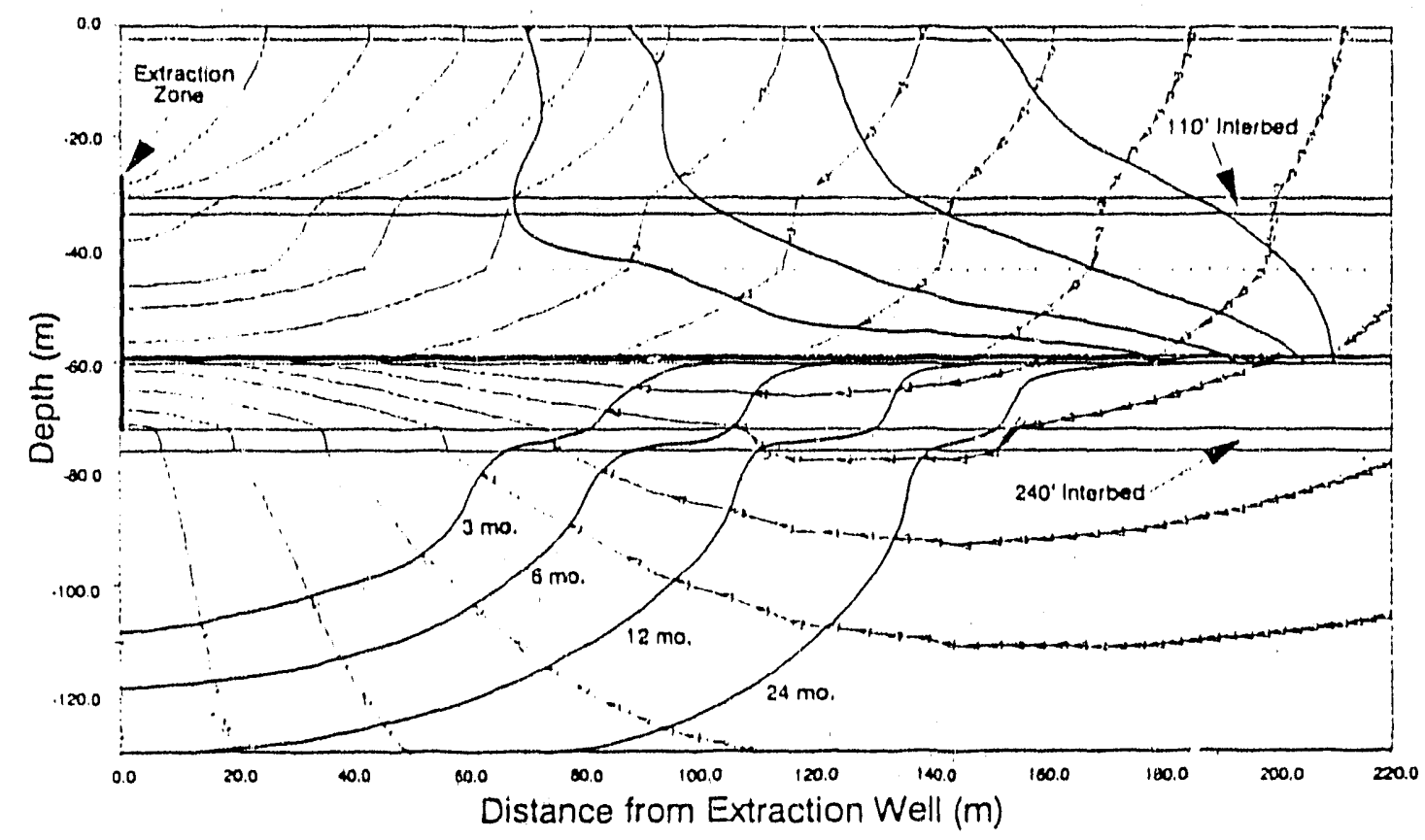

Figure 18. Soil gas flow pattern around the extraction well as a function of depth and radius. 
was evident in the field data as decreasing concentrations at depths below $167 \mathrm{ft}$ were noted in well 88010.

The estimated travel times from various points in the basalts to the extraction well are imposed on the flow patterns shown in Figure 18. Upon examination of these, it is possible that soil gas extracted from the $190-\mathrm{ft}$ rubble zone during the four month test could have come from monitoring wel1 D02 (150 $\mathrm{m}$ away). These travel times can be substantiated using cross bore hole tracer tests.

The VOC transport model will be calibrated based on concentrations observed in the monitoring wells over time, pressure drawdowns in nearby monitoring wells, and the use of tracer tests. Once calibrated, the transport model will provide VOC concentration distributions over time, extraction rates, and eventual cleanup times. These transport model results can be used to optimize future extraction well spacing, depth, and pump rates. 


\section{TEST SCALE VAPOR VACUUM SYSTEM OPERATION PROBLEMS AND CORRECTIVE ACTIONS}

The problems encountered during the operation of the TSVVE system included a HNu-201 gas analyzer spiking problem, HEPA filter fallures condensation in the HNU-201 gas analyzer sample lines, problems encountered during data collection, and DAS operation.

The spikes generated were indicated by the HNu-201 gas analyzer or when gross VOC concentration exceeded the $25 \mathrm{ppm}$ alarm limit on the exhaust side of the carbon beds when, in fact, concentrations did not exceed the aliarm limits. The problem was overcome with the installation of a five second time delay relay which required the $\mathrm{HNu}-201$ gas analyzer to generate the alarm trigger for at least five seconds to cause a shut down. The spiking problem was later attributed to a defective ultraviolet ionization tube. If a more maintenance free gross $V O C$ detector can be identified, it should be considered as a replacement instrument for the $\mathrm{HNu}-201$ gas analyzer.

The HEPA filter failed following the installation of the new extraction pump. While it is possible that condensation accumulated on the filters during the period of inactivity, rust particulate, welding slag, and quartz grains were found in the filter housing. The purpose of the cyclone separator was to prevent particulate from reaching the HEPA. Thus, particulate in the filter housing indicates that the cyclone separator did not perform as expected and should be replaced with a more reliable particulate trap.

Following detection of condensation in the HNu-201 gas analyzer sampling lines, heat tape was applied to the exposed tubing, and no further condensation problems were encountered.

Lab test results obtained during the last week of the test were compared to the Field GC and the differences were noted. A more stringent comparison using standard gases will be conducted to identify and resolve differences. Another problem has been the large fluctuations seen in reported 
concentrations. A QC procedure was put in place and has reduced the problem, but continuing effort needs to be expended in this area. One improvement would be to provide formal training to the GC operators in addition to the informal training conducted by field team leader.

During the operation of the DAS, a softwa's problem was encountered that caused the DAS to lose data over 24 hour periods in an intermittent fashion. The DAS vendor has provided new software and preliminary tests indicate the problem has been solved. 


\section{CONCLUSIONS}

During the four month test, the TSVVE system operated a total of 2090 hours; 65 million $\mathrm{ft}^{3}$ of soil gas was extracted, and $429 \mathrm{~kg}$ of $\mathrm{CCl}_{4}$, and $163 \mathrm{~kg}$ of TCE was removed from the basalts beneath the RWMC. Thus, VVE should be considered a viable remedial technology for removal of VOC from the RWMC.

Since $50 \%$ of the soll gas extracted originated from the rubble zone at $190 \mathrm{ft}$, the rubble zone dominated the gas movement pattern near the extraction we11. The presence of the rubble zone acted to increase the effective radius of the extraction well by producing a more vertical soil gas movement pattern. Thus, the rubble zone at $190 \mathrm{ft}$ will be an important consideration in the design of future systems.

A numerical model was formulated to match flow rates in the extraction well flow test. The preliminary modeling effort showed a strong pattern of vertical flow toward the rubble zone at $190 \mathrm{ft}$. A similar pattern was observed in soil gas concentration data. The model also indicated that travel times from the closest monitoring well to the extraction well ranged from one to several months. These model and field results indicate that concentrations as far as $50 \mathrm{ft}$ from the extraction well were affected. Extended operation would impact a larger region and trends in concentrations would become more clearly defined. These results together with pump test data indicate that extraction rates in the order of 2000 - $3000 \mathrm{scfm}$ can be achieved. Thus, TSVVE can be conside'"ed a viable interim remedial action. 


\section{REFERENCES}

Baca, R. G., J. C. Walton, and A. S. Road, 1988, "Organic Contaminant Release from a Mixed Waste Disposal Site: Analys is of Vapor Transport Through the Vadose Zone and Site Remediation," Proceedings of the Tenth Annual DOE Low-Level Waste Management Conference, Denver, CO. 1988.

Carslaw, H. S., and J. C. Jaeger, 1959, Conduction of Heat in Solids, Oxford University Press, pp. 510.

EG\&G Idaho, Inc., 1990, Remedial Investigation/Feasibility Study Work Plan for the Subsurface Disposal Area, Radioactive Waste Management Complex at the INEL, Draft, Idaho National Engineering Laboratory, EGG-WM-8776.

Leenheer, J. A., and Bagby, J. C., 1982, Organic Solutes in Ground Water at the Idab? National Engineering Laboratory, ID0-22061, U.S. Geological Survey, Water Resources Investigation 82-15, Idaho Falls, Idaho.

Rauen, C. D., 1990, Sampling and Analys is Plan for the Radioactive Waste Management Complex Subsurface Lisposal Area RECRA Facility Investigation/Corrective Measures Study Task: Vapor Yacuum Extraction, Rev. 2, EGG-WM-8381.

Spang, N. W., 1990, Health and Safety Plan for Operations Performed for the Environmental Restoration Program Task: Vapor Vacuum Extraction, Rev. 2, EGG-WM-8689.

Waltun et al., 1989, "Model For Estimation of Chlorinated Solvent Release from Waste Disposal Sites" Journal of Hazardous Materials, 21. 
APPENDIX A

THE FOUR MONTH TEST

START/STOP TIMES

$$
A-1 / A-2
$$


APPENDIX A

THE FOUR MONTH TEST START/STOP TIMES

Start

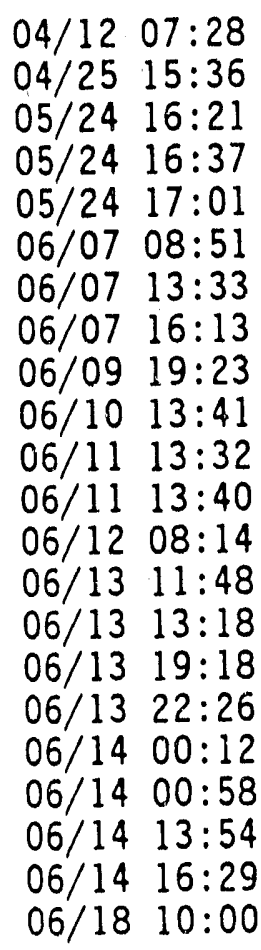

$06 / 18 \cdot 13: 16$

$06 / 19 \quad 14: 34$

$06 / 1915: 10$

$06 / 21 \quad 10: 34$

$06 / 21 \quad 13: 00$

$06 / 21 \quad 14: 28$

$06 / 28 \quad 13: 18$

$07 / 1016: 00$

07/12 11:06

$07 / 12 \quad 13: 56$

$07 / 12 \quad 14: 08$

$07 / 12 \quad 14: 20$

$07 / 12 \quad 14: 28$

$07 / 12 \quad 14: 48$

$07 / 16 \quad 13: 19$

$07 / 16 \quad 13: 27$

$07 / 16 \quad 13: 47$

$07 / 16 \quad 14: 15$

$07 / 16 \quad 14: 29$

Stop

$04 / 25 \quad 14: 54$

$05 / 10 \quad 07: 53$

$05 / 2416: 23$

$05 / 24 \quad 16: 43$

06/07 08:35

$06 / 07 \quad 12: 13$

06/07 16:11

06/09 19:11

06/09 19:41

$06 / 11 \quad 13: 18$

$06 / 11 \quad 13: 38$

06/12 08:04

$06 / 13 \quad 10: 52$

$06 / 13 \quad 12: 40$

$06 / 1318: 20$

$06 / 13 \cdot 20: 30$

$06 / 13 \quad 23: 22$

$06 / 14 \quad 00: 46$

$06 / 14 \quad 10: 41$

$06 / 14 \quad 13: 58$

$06 / 14 \quad 16: 34$

$06 / 18 \quad 13: 14$

$06 / 1816: 54$

$06 / 1915: 08$

06/19 15:12

$06 / 2112: 52$

$06 / 21 \quad 14: 26$

$06 / 21 \quad 15: 22$

$07 / 10 \quad 14: 35$

07/12 08:08

$07 / 12 \quad 11: 44$

$07 / 12 \quad 13: 58$

$07 / 12 \quad 14: 10$

$07 / 12 \quad 14: 24$

$07 / 12 \quad 14: 40$

$07 / 16 \quad 13: 17$

$07 / 16 \quad 13: 23$

$07 / 16 \quad 13: 43$

$07 / 16 \quad 13: 49$

$07 / 16 \quad 14: 23$

$07 / 1909: 26$
Cause

unknown

absorber swap

restart testing

restart testing

absorber sampling

HNu-201 Gas Analyzer

use other absorber

unknown

storm

check radon ports

install radon ports

unknown

unknown

unknown

unknown

unknown

unknown

unknown

planned work

same work

same work

check zero flow

reading

HNu-201 Gas Analyzer

spike

HNu-201 Gas Analyzer

spike

HNu-201 Gas Analyzer

spike

HNu-201 Gas Analyzer spike

R5 relay work

R5 relay work

install lab flowmeter

flow meter calibration

flow tests

reset HEPA alarm

flow tests

flow tests

flow tests

unknown

unknown

unknown

unknown

unknown

unknown 
Start

$07 / 19 \quad 10: 10$

$07 / 19 \quad 10: 18$

$07 / 19 \quad 10: 26$

$07 / 19 \quad 10: 42$

$07 / 19 \quad 11: 10$

07/20 09:18

$07 / 25 \quad 13: 47$

$07 / 25 \quad 15: 15$

$07 / 25 \quad 15: 35$

07/31 09:27

07/31 09:41

08/02 06:55

08/03 20:51

08/06 08:07

$08 / 07 \quad 13: 19$

$08 / 11 \quad 12: 43$
Stop

$07 / 19 \quad 10: 14$

$07 / 19 \quad 10: 22$

$07 / 19 \quad 10: 32$

07/19 11:04

07/19 19:40

$07 / 24 \quad 16: 03$

$07 / 25 \quad 13: 55$

$07 / 25 \quad 15: 27$

$07 / 25 \quad 15: 37$

07/31 09:37

08/02 05:41

$08 / 03 \quad 20: 47$

08/06 08:05

$08 / 07 \quad 13: 17$

$08 / 11 \quad 12: 37$

$08 / 13 \quad 08: 27$
Cause

unknown

unknown

unknown

unknown

unknown

end of 2 week hi flow test

DOP test failed

no smoke in generator

DOP test failed

DOP test passed restore system

unknown

unknown

unknown

to reset HEPA al arm

unknown

end of 4 month test 
APPENDIX B

PRODUCTION SCALE VAPOR VACUUM EXTRACTION SYSTEM CONSIDERATIONS 


\section{B-1. PRODUCTION SCALE VAPOR VACUUM EXTRACTION SYSTEM CONSIDERATIONS}

Implementation and system design enhancements can be achieved through further testing to delineate active sources of VOCs, better define the hydraulic properties of the underlying basalts, and more accurately determine the extent and mass of the contaminant piume. The design optimization requires tradeoffs between extraction zone depth; number, size, and depth of wells; extractor life expectancy; and operating costs.

\section{B-1.1 PSVVE RECOMMENDATIONS}

The number of extraction wells is an important design parameter because site cleanup requires the contaminant plume to be displaced with atmospheric air and a large number of wells would accelerate this process. A two level cleanup system that consists of shallow wells to extract the high concentration zones above the 110-ft interbed and a few we $11 \mathrm{~s}$ used to extract the low concentration zones found below the $190-\mathrm{ft}$ rubble zone should be considered.

A few wells that extract soil gas from the 190 -ft rubble zone would remove VOCs from the basalts, but could have the effect of drawing the contaminant plume above the $110-\mathrm{ft}$ interbed toward the Snake River Plain Aquifer. If the risk of moving the plume to deeper depths were deemed too high, a large number of shallow wells could be used to remove vocs from the shallow depths prior to pumping the $190 \mathrm{ft}$ rubble zone.

Man-made radionuclides were not detected at the extraction flow rates used during the four month test. Therefore, if man-made radionuciides are not detected at proposed higher flow rates, removal of the HEPA filter should be considered to improve efficiency of the VVE process. 

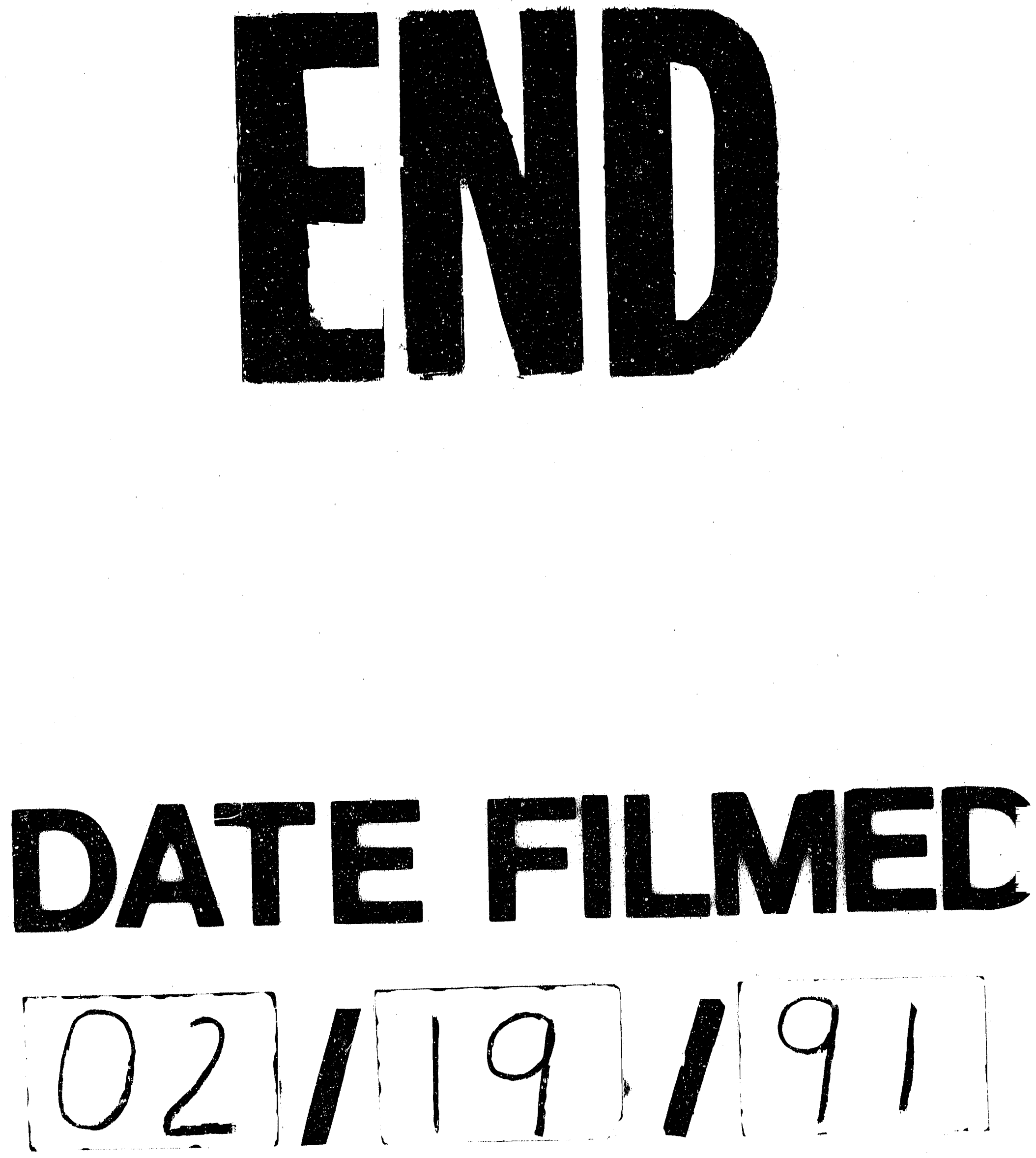
